\title{
Endocrinology of osmoregulation and thermoregulation of Australian desert tetrapods: A historical perspective.
}

Christine Elizabeth Cooper

Department of Environment and Agriculture, Curtin University, Perth, Western Australia, 6847.

School of Animal Biology, University of Western Australia, Crawley, Western Australia 6009

Corresponding Author:

Dr Christine Cooper

Department of Environment and Agriculture

Curtin University

POBox U1987 Perth

Western Australia 6847

Phone: +610892667965

e-mail C.Cooper@curtin.edu.au

Keywords: Endocrinology; Osmoregulation; Thermoregulation; Amphibian; Reptile; Mammal 


\begin{abstract}
Many Australian tetrapods inhabit desert environments characterised by low productivity, unpredictable rainfall, high temperatures and high incident solar radiation. Maintaining a homeostatic milieu intérieur by osmoregulation and thermoregulation are two physiological challenges faced by tetrapods in deserts, and the endocrine system plays an important role in regulating these processes. There is a considerable body of work examining the osmoregulatory role of antidiuretic hormones for Australian amphibians, reptiles and mammals, with particular contributions concerning their role and function for wild, freeliving animals in arid environments. The osmoregulatory role of the natriuretic peptide system has received some attention, while the role of adrenal corticosteroids has been more thoroughly investigated for reptiles and marsupials. The endocrinology of thermoregulation has not received similar attention. Reptiles are best-studied, with research examining the influence of arginine vasotocin and melatonin on body temperature, the role of prostaglandins in heart rate hysteresis and the effect of melanocyte-stimulating hormone on skin reflectivity. Australian mammals have been under-utilised in studies examining the regulation, development and evolution of endothermy, and there is little information concerning the endocrinology of thermoregulation for desert species. There is a paucity of data concerning the endocrinology of osmoregulation and thermoregulation for Australian desert birds. Studies of Australian desert fauna have made substantial contributions to endocrinology, but there is considerable scope for further research. A co-ordinated approach to examine aridhabitat adaptations of the endocrine system in an environmental and evolutionary context would be of particular value.
\end{abstract}




\section{Introduction}

Evolutionary adaptations of desert vertebrates have long been a source of interest to physiologists, as it is in arid environments that vertebrates must contend with conditions far removed from the aquatic habitats in which they originated (Williams and Tieleman 2001). The most characteristic feature of the Australian landmass is widespread aridity; $80 \%$ of the Australian landmass is semi-arid or arid (Bradshaw 1986; Heatwole 1987), therefore a significant proportion of Australian tetrapods inhabit desert environments. For example, the distribution of $>40 \%$ of Australian mammal species includes semi-arid or arid regions, and $>20 \%$ are restricted to these regions (Withers et al. 2004). All continents have deserts, but Australian deserts have especially low productivity (Bradshaw 1986, 2003) due to particularly variable and unpredictable rainfall coupled with ancient impoverished soils (Morton et al. 2011). Therefore, Australian deserts are particularly challenging environments for terrestrial vertebrates. As such, studies of the physiological mechanisms by which vertebrates persist in Australian deserts have been particularly important in improving knowledge of the adaptations of vertebrate animals to extreme environments in a global context.

Australia's fauna and its unique evolutionary history provide an ideal natural laboratory for examining the evolution of adaption to extreme arid environments. The ancient Gondwanan elements of Australia's tetrapod fauna, such as marsupials, ratites, chelid turtles and diplodactyline geckos, evolved in relative isolation on the Australian continent after the break-up of the supercontinent Gondwana during the Early Cretaceous (Heatwole 1987). These taxa diversified to fill a wide range of niches occupied by quite different and distantly related taxa on other continents, and such convergent evolution highlights common adaptations that address similar physiological challenges. Over time, this Gondwanan faunal element also had to adapt to a changing climate, as the Australian continent drifted northwards and became drier. In the Cenozoic, the Australian continent had a warm and humid climate, which underwent progressive drying throughout the Eocene and Oligocene. The first major step in the transition towards aridity was in the mid-Miocene, by which time paleo-drainage systems in northwestern Australia had ceased to flow. This aridity spread into the centre of the continent throughout the remaining Miocene. The primarily arid and semiarid climate of modern Australia was established by the end of the Pliocene, with arid glacial and humid interglacial cycles occurring throughout the Pleistocene. At present there is a particularly dry interglacial phase, reflecting the very dry preceding glacial maximum 
(Heatwole 1987; Martin 2006; Morton et al. 2011). In addition to a warmer and drier climate, Australia's northward drift has also brought the continent into close proximity with southeast Asia, and a considerable proportion of Australia's current fauna including rodents, most lizards and snakes and many birds, represents more recent invasions from southeast Asia since the Tertiary (Heatwole 1987). Many of these groups have adapted to desert environments and have become a conspicuous element of Australia's desert fauna. Finally, human-introduced invasive species such as cane toads, house mice, rabbits, goats, camels, donkeys and cats provide another more recently introduced faunal element for examination of a more recent response to Australia's desert habitats.

Maintaining a homeostatic internal environment (milieu intérieur) by the processes of osmoregulation and thermoregulation are two particular physiological challenges faced by terrestrial animals in desert environments. Deserts by their very definition are arid habitats where evaporation exceeds precipitation (Williams and Tieleman 2001), therefore osmoregulation, or the maintenance of water and solute levels constant or within the range of tolerance (Shoemaker and Nagy 1977) is an obvious physiological challenge. This is especially true in Australian deserts where there may be many years of extreme aridity interspersed by occasional heavy rain and flooding (Morton et al. 2011). Australian deserts are also hot deserts (Bradshaw 1986; Williams and Tieleman 2001), and the extreme ambient temperatures and high incident solar radiation experienced by Australian desert vertebrates are exacerbated by the paucity of free water availability; this impacts on the capacity for evaporative heat loss at high ambient temperatures. Thus Australian desert vertebrates also face considerable thermoregulatory challenges.

Hormones are chemical messengers released into the bloodstream by endocrine glands, in response to specific stimuli. Hormones act on specific target organs that have the appropriate receptor molecules and elicit a wide range of responses. The endocrine system plays a role both in the chronic regulation and acute response of a wide range of physiological processes, including osmoregulation and thermoregulation, and therefore the endocrinological control of water, salt and thermal balance is of particular importance to desert vertebrates. Examining the response of Australian desert vertebrates to the extreme osmoregulatory and thermoregulatory challenges of their environment can enlighten us about not only the mechanisms, but also the environmental function and evolution of homeostatic systems and processes. I review here how studies of Australian desert terrestrial vertebrates have 
contributed to, and continue to, advance our knowledge of the endocrinological control of osmoregulation and thermoregulation of terrestrial vertebrates.

\section{Amphibians}

Amphibians represent the transition of tetrapod vertebrates from an aquatic to a terrestrial environment and so their osmoreguatory strategies are of particular interest to physiologists. The osmoregulation of amphibians differs substantially from both aquatic fish and terrestrial amniotes, with their general use of cutaneous aerial respiration and subsequent requirement for a permeable skin impacting greatly on their osmoregulatory requirements and processes (Bentley 2002). Four hormonal systems, the hypothalamo-neurohypophysial system, the renin/angiotensin/aldosterone system, the adrenocorticotrophic (ACTH)/corticosteroid system and the natriuretic peptide system, play a primary role in amphibian osmoregulation, with lesser roles for hormones including insulin, prolactin, hydrins and guanylins (Uchiyama and Kono 2006). Amphibians' capacity for thermoregulation is relatively poorly developed compared to other tetrapods due to their highly permeable skin, but some species, such as "waterproof" frogs including Litoria, do show some regulation of body temperature $\left(\mathrm{T}_{\mathrm{b}}\right)$ relative to ambient temperature.

Of the three extant amphibian orders, only the anurans inhabit Australia. There are two major, widespread families of native Australian anurans, the Hylidae or tree frogs and the Myobatrachidae or southern ground frogs. The ancient myobatrachid frogs in particular have radiated to fill a wide variety of niches, but are typically a xerophilous group that have become a conspicuous element of Australia's deserts (Bentley 2002). Studies of the endocrinology of these myobatrachidid frogs can reveal adaptive strategies that have allowed these unlikely desert inhabitants to become such a successful element of Australia's arid zone fauna, but surprisingly, these studies are few, reflecting the generally limited knowledge concerning comparative endocrinology of amphibians worldwide (Uchiyama and Konno 2006) and preventing the informative analysis of endocrine function in an ecological and phylogenetic context necessary to fully explore the evolutionary significance of variation in amphibian osmoregulation.

\section{Osmoregulation}

The most spectacular adaption of Australian myobatrachidid desert frogs to surviving the inhospitable desert conditions of high temperatures and little free water is their ability to 
withstand long periods of aestivation, burrowed below the desert substrate. Some burrowing desert frogs, including the genera Neobatrachus and Cyclorana, form a cocoon of shed skin layers providing a barrier to evaporative water loss from the skin (Withers, 1995). Others such as Heleioporus, Notaden, Arenophryne and Myobatrachus burrow into soil with a favourable water potential (Cartledge et al., 2006a\&b; Thompson et al., 2005). Behaviours such as aestivation and cocoon formation are presumably under hormonal control, but hormonal changes that reduce activity, prevent consumption of shed skin layers and possibly contribute to metabolic depression have not yet been identified (Bentley 2002); this is an important direction for future research.

The only studies of the major osmoregulatory hormone arginine vasotocin (AVT) for Australian desert frogs are for the burrowing myobatrachid frogs Cyclorana platycephala, Neobatrachus aquilonius and Notaden nichollsi. The interrelationship between aestivation period, plasma and urine osmolality and plasma AVT concentration was examined for the arid-habitat, cocooning, water-holding frog C. platycephala by Cartledge et al. (2008), for frogs aestivating in the laboratory for up to 15 months. During this period, plasma osmolality increased from initial levels of $250 \mathrm{mOsm}$ to $487 \mathrm{mOsm}$ after 9 months, then remained stable for the rest of the aestivation period. Urine osmolality, however, continued to increase until 15 months aestivation, by which time it was iso-osmotic (469 $\pm 31.3 \mathrm{mOsm})$ with the plasma (501 $\pm 31.2 \mathrm{mOsm})$, indicating that frogs were re-absorbing water from the bladder to replace that lost by evaporation. Despite the general role of AVT contributing to osmoregulation by controlling the excretion of water from the kidneys in response to increased plasma osmolality (Bentley 2002; McCormick and Bradshaw 2006), there was no clear relationship between plasma AVT concentrations and osmolality during the 15 month aestivation period, and no increase in AVT over time, so the role in AVT in regulating this process for these frogs is unclear. However, when 15 month aestivating frogs were placed in water to rehydrate, plasma AVT declined rapidly, possibly to reduce vasodilation and enhance water uptake (Cartledge et al. 2008), or to facilitate urine production for excretion of accumulated urea.

Despite burrowing frogs being an important component of desert fauna worldwide, the difficulty in locating and accessing frogs during aestivation in the wild previously precluded research on their osmoregulation in the field. Cartledge et al. (2006a) carried out a unique 
study of the hygric physiology of aestivating burrowed desert frogs in the field. Neobatrachus aquilonius and Notaden nichollsi, which had been aestivating for 8 months to 1.5 years in Western Australia's Gibson Desert, were located with the assistance of Aboriginal people and dug from sand dunes, swales and claypans, providing the only information concerning the endocrinology of osmoregulation during aestivation for wild, free-living anurans. Both species of aestivating frog had similar plasma AVT levels of 9.4 to $164 \mathrm{pg} \mathrm{ml}^{-1}$ that did not differ significantly from that of hydrated, non-aestivating individuals with AVT levels of approx. $40.2 \pm 8.9 \mathrm{pg} \mathrm{L}^{-1}$. Apart from a single cocooned $N$. aquilonius that appeared to have reached its water balance threshold with isomotic plasma and urine, there was no significant relationship between plasma AVT and osmolality for either species of aestivating frog. The authors concluded that the majority of aestivating frogs in the field were not yet experiencing any substantial volumetric or osmotic stress as their behavioural strategies of forming a highly water resistant cocoon or remaining in soil with a favourable water potential allowed them to aestivate for extended periods before they reached a threshold where AVT secretion would be enhanced.

These studies of AVT concentrations for Australian frogs make an important contribution to our understanding of endocrinological adaptations of amphibians to desert environments by providing the only measures of AVT concentration for aestivating amphibians, including data for wild, free-living frogs in their natural environment. However, with so few studies for comparison, it is somewhat difficult to interpret the results. There appears little consistent increase in AVT concentrations of aestivating myobatrachid frogs in both the laboratory and the field compared to control values for fully hydrated individuals. Both control and aestivation AVT concentrations appear to be higher than those of hydrated terrestrial and aquatic frogs in the laboratory e.g. Bufo $28 \mathrm{pmol} \mathrm{L}^{-1}$, Rana. 5.5 to $17 \mathrm{pg} \mathrm{ml}^{-1}$, and are often more comparable to Bufo and Rana frogs that had been dehydrated, placed in hypertonic solutions or were post haemorrhage (Pang 1977; Sawyer and Pang 1975; Nouwen and Kühn 1983; Kono et al. 2005). Given the relatively high control AVT levels for myobatrachid frogs it is possible that these Australian desert burrowing frogs have a high background AVT concentration as an adaption to periodic aestivation, or high AVT levels may be a phylogenetically determined characteristic of these anurans. Without further data for a wider array of amphibian species from Australia and worldwide it is currently difficult to interpret these comparisons in an ecological or phylogenetic context. 
Toads of the genus Bufo are used globally as amphibian models for a wide range of physiological and anatomical studies. Cane toads (Chaunus previously Bufo marinus) were introduced into Australian cane fields in 1935 and have since extended their range into tropical, semi-arid and even arid areas of northern and western Australia, becoming a major ecological pest (Urban et al. 2007). They are widely available (despite strict quarantine restrictions in some Australian states) for research purposes and, as in other countries, Australian cane toads have contributed to our understanding of amphibian physiological mechanisms. J.A. Donald and colleagues have used Australian cane toads as a model to examine the role of natriuretic peptides (NPs) in amphibian osmoregulation. Generally NPs control blood volume by regulating water and salt excretion (Bentley 2002; McCormick and Bradshaw 2006). There are potentially four target organs in amphibians on which NPs could act to contribute to osmoregulation; the kidneys, urinary bladder, adrenal glands and skin, and studies of NP action for Australian cane toads has contributed to knowledge of two of these, the kidney and urinary bladder (Donald and Trajanovska 2006). Donald et al. (2002) identified a preproatrial natriuretic peptide (preproANP) from cane toads, that shared 66 to $72 \%$ similarity of amino acid sequences to preproANP from two other amphibian species (Xenopus laevis and Rana catesbeiana respectively), with amino acids 1-24 identical to those of the genus Rana. There was a significant effect of ANP (1-24) on renal function in toads, with renal natriuresis and diuresis resulting from an increase in glomerular filtration rate occurring in response to arterial perfusion of frog ANP into a perfused toad kidney preparation. This suggests that preproANPs may function in the maintenance of overall fluid volume via action on the kidneys. Indeed Meier et al. (1999) identified ANP binding sites on cane toad glomeruli and blood vessels within the kidney but not renal tubules, providing support for the role of the kidney in NP-mediated osmoregulation. This was an important finding, considering the previously limited data concerning NP control of amphibian renal function (Donald and Trajanovska 2006). In the cane toad bladder, messenger ribonucleic acid (mRNA) for both NP receptor-A and C receptor types was expressed, possibly reflecting the terrestriality of cane toads compared to other frogs in which ANP binding sites appeared to be absent in the bladder (Meier and Donald 2002). However, ANP had no effect on water permeability or vascular resistance of perfused toad bladders so the role of NP receptors in the toad urinary bladder remains unclear. Future investigation of specialised arid habitat frogs, such as Australian desert burrowing myobatrachids, may reveal the suggested pattern of ANP binding site with increased terrestrially and desiccation resistance. 
In addition to direct effects on peripheral osmoregulatory organs, NPs may impact on osmoregulatory balance via effects on the cardiac system and central nervous system (Donald and Trajanovska 2006). Minerds and Donald (2001) demonstrated the expression of mRNA for the NP receptor NPR-A in cane toad aortae, and that ANP resulted in production of guanosine 3':5'-cyclic monophosphate (cGMP) in the membranes of blood vessels, suggesting cGMP facilitates NP mediated vasodilation, although no effects of ANP were found on cane toad cardiac function (Minerds and Donald 1997). McLeod and Donald (1999) found NP immunoreactivity in the cane toad brain, with the densest distribution in the preoptic/hypothalamic region of the diencephalon and the interpeduncular nucleus of the mesencephalon, brain areas believed to play an important role in osmoregulatory balance. NP receptor-C and guanyl cyclase mRNA were located in the toad brain, with NP binding sites most densely distributed in the dorsal pallium, the habenular region, the torus, semicircularis, the choroid plexus, and the pituitary (McLeod and Donald 2000). Differences in neural binding sites between frog and toad species suggests varied neural action of NPs amongst amphibians (Donald and Trajanovska 2006), and again this area of investigation would benefit from a systematic exploration of neural binding sites for an array of anuran species from varied phylogenetic histories and ecological niches.

\section{Thermoregulation}

The cutaneous resistance of most frogs to water loss is equivalent to that of a free water surface at $1 \mathrm{sec} \mathrm{cm}^{-1}$, but some frogs, known as "waterproof" frogs, have much higher resistances, as high as $100 \mathrm{sec} \mathrm{cm}^{-1}$. Amongst Australian frogs, it is not the desert dwelling myobatrachid burrowing frogs that have relatively high skin resistances (except when cocooned), but rather the tree frogs of the family Hylidae. "Waterproof" frogs, including Australian species of the genus Litoria, may exploit their reduced cutaneous evaporative water loss to bask in exposed locations, increasing their $\mathrm{T}_{\mathrm{b}}$ (Buttemer and Thomas 2003; Withers 1995). Many basking frogs have been observed to blanch the skin, and it has been presumed that they do this to reduce solar heat gain and prevent overheating (e.g. Tattersall et al. 2006; Withers 1995). Blanching by the arid-habitat Australian tree frog Litoria rubella is a consequence of aggregated melanophores, and significantly increases the dorsal reflectance, from $18.8 \%$ for a dark frog with a chromatophore index of 5 to $31.8 \%$ for a light coloured frog with a chromatophore index of 2. Interestingly, for L. rubella maintained in the laboratory in the absence of solar radiation, blanching occurred in response to dry air (Withers 1995). I suggest here that one possible interpretation of this phenomenon is that 
blanching during basking may not actually be a mechanism to prevent overheating as assumed previously, as why do frogs not simply cease basking when they reach a $T_{b}$ requiring a reduction in solar heat gain? Rather it may be a water conservation mechanism, whereby pale skin with a high reflectance reduces evaporative water loss by reducing the skin surface temperature and therefore the water vapour pressure at the skin surface. This would provide a more favourable trade-off between the thermoregulatory benefits and water balance costs associated with basking. Laboratory experiments to directly test this hypothesis may prove informative. Although not measured directly for blanching waterproof frogs, it is assumed that the colour changes associated with thermo- or hygro-regulation are under endocrine control, as hormonal as opposed to nervous control of colour pigments predominates amongst the amphibians; melatonin is their primary pigment aggregating hormone (Sköld et al. 2012).

\section{Reptiles}

Studies of Australian desert squamates have contributed greatly to understanding the endocrinology of osmoregulation and thermoregulation in reptiles, with much of this knowledge attributable to S.D. Bradshaw and his colleagues. The osmoregulation of reptiles is of particular interest, as they are an iconic element of Australian deserts and indeed deserts worldwide, but they lack the specialised anatomy and physiology of mammalian and avian kidneys, and are therefore unable to produce urine that is hyperosmotic compared to their blood (Bradshaw and Bradshaw 2002; Ford and Bradshaw 2006). In addition, there can be a considerable thermoregulatory trade-off for these ectotherms, associated with maintaining an optimal temperature for activity and conserving scarce resources, particularly water, in a hot and dry environment.

\section{Osmoregulation}

As for other tetrapods, AVT plays a major role in osmoregulation for reptiles, and considerable work on Australian desert species has contributed to our identification and understanding of this important endocrine role. AVT conserves water in response to increased plasma osmolality by impacting on both renal and extra-renal osmoregulatory organs (Bradshaw 1972). Bradshaw $(1975,1976)$ provided some of the first evidence that in reptiles AVT from the hypothalamic nuclei travels to the pars nervosa via neurosecretory axons in the base of the hypothalamus, from where it is released into the circulatory system in response to an increase in plasma osmotic pressure. For salt-loaded ornate dragon lizards 
(Ctenotus formally Amphibolurus ornatus), surgically-introduced lesions on the hypothalamo-hypophyseal tract prevented AVT secretion and abolished the antidiuresis that was apparent for control animals. However, injection of these operated individuals with AVT reinstated the expected antidiuretic response (Bradshaw 1975, 1976).

The first measurements of circulating plasma AVT levels in a reptile were made for the Australian desert goanna Varanus gouldii (Bradshaw and Rice 1981, Rice 1982). Bradshaw and Rice (1981) made a particularly important contribution to understanding reptilian osmoregulation, as they examined a complete picture of the mechanisms, response and regulation of kidney function for this single species; previously an overall understanding of reptilian renal function had to be gleaned from a composite of different studies for a variety of species (Bradshaw 1997). Bradshaw and Rice (1981) quantified both glomerular and tubular contributions to the goannas' physiological response of antidiuresis to dehydration and salt-loading, and determined that circulating AVT, which was elevated in dehydrated and salt loaded goannas, was the likely control mechanism mediating the response. Dehydrated and salt-loaded goannas increased plasma AVT levels to $240 \%$ and $438 \%$ of that of hydrated goannas respectively, and plasma AVT was positively correlated with plasma osmolality. Furthermore, goannas injected with AVT significantly reduced glomerular flow rates, relative free-water clearance and urine volume, and increased tubular reabsorption, while a subsequent probenecid injection to block AVT action removed these effects (Bradshaw and Rice 1981; Rice 1982). Therefore, AVT influences glomerular filtration and both salt transport and water reabsorption from the renal tubles (Bradshaw 1997). Further correlations of circulating AVT and plasma osmolality have subsequently been measured for arid and mesic habitat tiger snakes (Notechis scutatus; Ladyman et al. 2006).

It is hypothesised that the effect of AVT on reptilian glomeruli is via $\mathrm{V}_{1}$-type receptors leading to constriction of glomerular arterioles and a consequential reduction in glomerular filtration rate, although no $\mathrm{V}_{1}$ receptor has yet been identified for reptiles (Bradshaw and Bradshaw 1996, 2002; Ford and Bradshaw 2006). $\mathrm{V}_{2}$-type receptors have, however, been identified in the renal tubule, occurring in the intermediate segment, branched collecting ducts and the main collecting duct of the arid-habitat ornate dragon lizard, where they facilitate tubular responses such as relative free-water and osmolar clearances (Bradshaw and Bradshaw 1996). 
Ford and Bradshaw (2006) explored ecological correlates of AVT mediated kidney function for three species of agamid lizard from an environmental aridity gradient (bearded dragon, Pogona minor, mesic; claypan dragon, Ctenophorus salinarum, semi-arid; central netted dragon, Ctenophorus nuchalis, arid). All three species showed an antidiuretic response, mediated by AVT, to dehydration and hypernatraemia, achieved by adjustments to both glomerular and tubular function, although these adjustments were primarily glomerular for the mesic-habitat bearded dragon when salt-loaded. Bearded dragons had a more extreme antidiuretic response compared to the arid and semi-arid habitat species, suggesting that they were more challenged by perturbation of their osmotic balance. However, the majority of hormonal and functional aspects of the observed renal response were similar for all species, leading the authors to conclude that these dragon lizards show limited adaption of their renal system to varying environmental aridity and supporting the idea that squamate reptiles may be pre-adapted to arid habitats by their general physiological bauplan (Ford and Bradshaw 2006). This idea is supported by the radiation and subsequent diversity of squamate reptiles in Australia's arid zone, despite their relatively recent evolutionary history as inhabitants of arid areas on this continent (Heatwole 1987).

Adrenal corticosteroids are involved in maintaining electrolyte balance in reptiles. Their function as natriuretic hormones is particularly important for eliminating excess solutes, considering that AVT enhances solute reabsorption in response to hypernatraemia (Bradshaw 1997). An increased plasma $\mathrm{Na}^{+}$concentration is correlated with an increase in corticosteroidogenesis, and increased urine concentration for the ornate dragon lizard, a species which lacks a nasal salt gland and relies on renal function for solute homeostasis (Bradshaw 1972). Plasma corticosteroid concentrations increased significantly after eight days of salt loading and decreased significantly after eight days of water loading. Injection of corticosterone and mammalian ACTH increased both urine sodium concentration and daily sodium excretion of salt-loaded dragons compared to controls, while hypophysectomy and injection with the synthetic hormone dexamethasone, that inhibits the secretion of ACTH, increased sodium reabsorption. These findings strongly support the functioning of a pituitaryadrenal axis for reptiles, with ACTH from the pituitary mediating secretion of corticosteroids from the adrenal glands; hypernatremia appears to have little direct effect on the adrenals (Bradshaw 1972). 
Aldosterone is the second major adrenocorticosteroid of the reptilian adrenal gland. It functions as a mineralocorticoid on the kidney, increasing potassium excretion and reducing loss of sodium, but does not appear to impact on osmoregulatory roles of the colon (Bradshaw and Rice 1981). Circulating plasma concentrations of aldosterone were first measured by Bradshaw and Grenot (1976) for the Australian arid-adapted bobtail skink (Tiliqua rugosa) and the Algerian spiny-tailed lizard (Uromastix acanthinurus), and levels for control animals were found to approximate those of mammals. Chronic salt-loading reduced circulating aldosterone levels, as did inhibition of ACTH secretion with dexamethasone. Adrenalectomy is technically difficult with reptiles, but it has been achieved for a number of species including the Australian Gould's goanna (Rice et al. 1982). Adrenalectomised goannas had significantly reduced plasma potassium levels, although sodium levels were unaffected. Adrenalectomy did not impact on the goanna's physiological response to hypernatremia, but these individuals did not reduce their fractional reabsorption of sodium or chloride when water-loaded; they were not able to increase their excretion of the excess water or conserve sodium and chloride ions. Injection of exogenous aldosterone, however, increased the fractional reabsorption of sodium for both water and salt-loaded animals. These data strongly support the idea that aldosterone is a physiological mineralocorticoid that acts to reduce sodium and enhance potassium excretion (Rice et al. 1982).

The varying actions of AVT and adrenal hormones for "normal", dehydrated and hypernatremic arid-zone reptiles are best understood when a holistic overview of their combined function is considered. A synthesis of endocrinological work on Austrian arid habitat reptiles allows for this overview (Figure 2). If a lizard becomes dehydrated, it attempts to maintain homeostasis by conserving water. AVT levels increase, resulting in antidiuresis, but also reabsorption of salts. Retention of sodium is further enhanced, but potassium is excreted, by increased aldosterone levels, and decreased corticosteroid levels. Therefore, the animal reduces renal water loss by conserving sodium, in the absence of a mechanism to concentrate urine to levels greater than blood plasma (Bradshaw 1992). Saltloading, however, also increases AVT, but the natriferic effect of the AVT is overcome by the increase in corticosterone and decrease in aldosterone levels, maximising solute extraction while maximally conserving water (Bradshaw 1992). These responses to dehydration and salt loading explain field observations of marked hypernatraemia for aridhabitat Australian reptiles in summer (e.g. Bentley 1959; Bradshaw 1970; Braysher 1976), particularly those with high sodium diets and no nasal salt glands. During dry periods when 
drinking water is unavailable, these lizards accumulate large volumes of extracellular fluid that is high in sodium, a consequence of maintaining normal total body water content by becoming hypernatraemic. When fresh water is available, the lizards drink and rapidly restore normal extracellular fluid and sodium levels. However, extended periods of dryness can lead to dehydration; some Australian lizards can withstand up to a $40 \%$ body mass loss. These lizards maintain hydrated-equivalent plasma and blood volumes by reducing first the intracellular water content, and then extracellular fluid volume at the expense of the interstitial fluid volume, to maintain circulating fluid volumes. Plasma and tissue sodium concentrations increase with dehydration to facilitate water conservation, although potassium is homeostatically regulated (Bradshaw 1986).

\section{Thermoregulation}

Most reptiles are ectotherms, and as such use a suite of behavioural and physiological mechanisms to influence their rate of external heat gain and loss, and thus regulate their $T_{b}$. The endocrine system is an important physiological control system that contributes to reptile thermoregulation, with hormones including the anti-diuretic hormone AVT, prostaglandins, $\alpha$-melanophore stimulating hormone $(\alpha-\mathrm{MSH})$, the pineal hormone melatonin, and the reproductive hormone progesterone all potentially contributing to regulation of reptilian $T_{b}$. These various hormone systems influence $\mathrm{T}_{\mathrm{b}}$ set-point, heating and cooling rates, and skin colouration.

The lowering of preferred $\mathrm{T}_{\mathrm{b}}$ (PBT) by dehydration and electrolyte loading for lizards has been recognised since the late 1980s, but until relatively recently little was known about the extent of, and mechanism(s) for, this (Bradshaw et al. 2007). Ladyman and Bradshaw (2003) found that Australian tiger snakes, like lizards, also initiated this thermoregulatory response of lowered PBT to osmoregulatory stress. Dehydrated tiger snakes had a lower PBT, with reduced upper and lower limits to preferred $\mathrm{T}_{\mathrm{b}} \mathrm{S}$ (UPBT, LPBT respectively) compared with hydrated snakes. Tiger snakes from a semi-arid offshore island had a more pronounced thermoregulatory response to dehydration, reducing PBT and average maximum temperature significantly more than snakes from a mesic mainland swamp. This presumably reflects regular periods of seasonal dehydration observed for island tiger snakes, and can be interpreted as an important response to conserve water in a semi-arid environment, as a reduced PBT presumably reduces evaporative water loss (Ladyman and Bradshaw 2003). Bradshaw (1997) was the first to suggest that AVT may influence this PBT response to 
dehydration, based on studies of the ornate dragon lizard, a species which experiences periodic aridity and has a high-salt diet. Further investigation into the mechanism of a thermoregulatory response to osmoregulatory stress by Ladyman and Bradshaw (2006) found that tiger snakes from a semi-arid island reduced PBT in response to injection of AVT, independent of any changes in plasma osmolality (Figure 2), compared to control shaminjected snakes, and levels of plasma AVT measured for experimentally salt-loaded hypernatraemic snakes were significantly correlated with plasma sodium concentration and osmolality. These AVT measurements were only the second measurements of AVT for any snake species. The authors concluded that a reduction of PBT in response to increased plasma osmolality is a consequence of elevated AVT, and functions to conserve water when this vital resource is scarce. Additional experimental evidence for the ornate dragon (Bradshaw et al. 2007) confirmed reduced PBT of approximately $2^{\circ} \mathrm{C}$ for lizards with elevated plasma sodium. However, after surgical lesioning of the hypothalamus to prevent secretion of AVT, hypernatraemic lizards no longer reduced PBT, although injection of AVT reinstated this response. This provided the first clear evidence that the secretion of AVT mediates the observed thermoreguatory response of reptiles to hypenatraemia. Therefore, AVT is a waterconserving hormone that not only functions via its anti-diuretic impact on the renal system, but also influences thermoregulatory behaviour, allowing squamates to trade-off energetic and osmotic demands, and conserve water in response to perturbation of the milieu intérieur.

The efficacy of behavioural thermoregulation by reptiles is enhanced by physiological control of heat transfer between the body surface and core. Heart rate hysteresis is the phenomenon where reptiles have higher heart rates during heating than they do during cooling, for any given $T_{b}$. These changes in heart rate are directly related to changes in peripheral blood flow, and ensure that reptiles heat faster than they cool, maximising the period of optimal $T_{b}$ (Seebacher and Franklin 2004, 2005). This phenomenon has been widely recognised by laboratory studies, but work on two Australian species, the eastern bearded dragon (Pogona barbata; Grigg and Seebacher 1999) and the lace monitor (Varanus varius; Seebacher and Grigg 2001) confirmed that heart rate hysteresis is an important thermoregulatory mechanism for wild, free-ranging animals in the field, with direct functional significance. The important role of heart rate hysteresis raises the question as to how this thermoregulatory response is regulated. Although the nervous system plays a role in controlling heart rate during heating and cooling via cholinergic and $\beta$-adrenergic mechanisms, pharmacological blocking of their receptors did not abolish the hysteresis response for Australian eastern bearded dragons 
(Pogona barbata; Seebacher and Franklin 2001). Further studies with the Australian aridzone central bearded dragon (Pogona vitticeps) showed endocrine control via prostaglandins, which function to control both increases and decreases in heart rate during warming and cooling via their action on peripheral blood vessels (Seebacher and Franklin 2003). Prostaglandins are formed by the action of cyclooxygenase (COX) enzymes on arachidonic acid, and dilate or constrict blood vessels. Their proposed mode of action on the heart is via a barostatic reflex in response to peripheral blood vessel dilation or constriction, and possibly some direct effect of prostaglandin $\mathrm{F}_{2 \alpha}$ on the heart muscle itself. For central bearded dragons, the normal heart rate hysteresis observed for control animals during warming and cooling was completely abolished when COX enzymes were inhibited with diclofenac; heart rate for these treatment animals changed as expected from the $\mathrm{Q}_{10}$ effect of $\mathrm{T}_{\mathrm{b}}$ i.e. the expected change in rate per $10^{\circ} \mathrm{C}$ change in $\mathrm{T}_{\mathrm{b}}$. Treatment of dragons with the agonists prostaglandin $F_{2 \alpha}$ and prostacyclin resulted in significantly elevated heart rates (Seebacher and Franklin 2003). In this way, the endocrine system plays an important role in regulating the cardiovascular system to optimise thermoregulatory responses, extending the potential active period of reptiles.

Reptiles can modify the reflectivity of their skin by concentrating or dispersing melanin in dermal melanocytes, a process that is under both neural and endocrine control (Bradshaw 1997). The pituitary hormone $\alpha-\mathrm{MSH}$ disperses melanin, making the integument darker. Darker lizards heat more quickly than paler lizards e.g. the Australian central netted dragon and the blue-tongued skink (Tiliqua scincoides; Geen and Johnston 2014; Rice and Bradshaw 1980; but see Fraser 1985). For central netted dragons, injection of $\alpha$-MSH resulted in 0.43 ${ }^{\circ} \mathrm{C} \min ^{-1}$ more rapid heat gain compared to control dragons, while hypophysectomised dragons, that were permanently pale in the absence of $\alpha-\mathrm{MSH}$, heated $0.31{ }^{\circ} \mathrm{C} \min ^{-1}$ more slowly than controls. Injection of $\alpha$-MSH into hypophysectomised lizards increased their rate of heating back to that of the control animals. There were no differences in cooling rates between the two treatments and the controls, as expected (Rice and Bradshaw 1980). This study provides clear evidence that endocrinological control of skin reflectance plays an important role in the thermoregulation of reptiles.

Thermoregulatory response to the pineal hormone melatonin is arguably one of the most widely-studied but poorly understood aspects of the endocrinology of thermoregulation for reptiles. Work on Australian species, particularly the desert-adapted bobtail skink has 
contributed to our understanding of the influence of both photophase and thermophase on circadian melatonin secretion, and therefore on activity and potential for thermoregulatory behaviour, but our understanding of the direct role of melatonin in influencing the $T_{b}$ set point and associated behavioural responses is poor for all reptiles, due in part to variable responses between species (Bradshaw 1997; Lutterschmidt et al. 2003). There is a poor understanding of ecological variation and adaptive function for melatonin-controlled thermoregulation. In general, melatonin secretion is considered to reduce $T_{b}$, presumably by adjusting the $T_{b}$ set point in the hypothalamus (Lutterschmidt et al. 2003). Plasma melatonin rhythms for bobtail skinks are typical of those of other reptiles specifically, and vertebrates generally, being lower in the light phase and higher during the dark phase (Firth et al. 1979, 2006). This melatonin rhythm has a circadian component, persisting for at least 6 days in 24 hour darkness, but can be abolished by constant exposure to light (Firth et al. 2006). Thermal variation impacts on this melatonin rhythm; a thermal cycle synchronised with the photophase enhances the $T_{b}$ rhythm, but an out-of-sync thermophase disrupts the rhythm for both bobtails (Firth and Kennaway 1980, 1987, 1989; Firth et al. 1991) and the marbled gecko (Christinus marmoratus; Moyer et al. 1997). For bobtails (and the tuatara; Sphenodon punctatus), a thermal threshold is apparent for the establishment of a melatonin rhythm (Firth and Kennaway 1987), and this threshold was higher at $\sim 25^{\circ} \mathrm{C}$ for the desert-adapted bobtail than it was for the cool-habitat tuatara at $\sim 15^{\circ} \mathrm{C}$. Therefore, both temperature and light influence pineal secretion of melatonin, and this relationship is moderated by habitat. Melatonin secretion may be influenced by the function of the parietal eye. The parietal eye of bobtails was found to contain melatonin, the levels of which, along with blood and pineal gland levels, fluctuated in response to temperature and light cues (Firth and Kennaway 1987). Surgical removal of the parietal eye abolished the plasma melatonin rhythm, by increasing the light phase and decreasing the dark phase levels in the blood plasma. Covering the lateral eyes however did not affect the plasma melatonin rhythm (Firth and Kennaway 1980). Presumably, a combination of thermal and light cues detected at least in part by the parietal eye influence melatonin section, which contributes to the maintenance of observed daily and seasonal patterns (Elis et al. 2007, 2008) in activity and thermoregulation (Firth et al. 1989).

\section{Birds}

There is a surprising paucity of data concerning the physiology in general of Australian birds, both in terms of the total number of studies, and the number of species investigated (Astheimer and Buttemer 2002). As a result, the study of Australian species has contributed 
little to understanding the endocrinology of osmoregulation and thermoregulation and how birds adapt to arid environments. Astheimer and Buttemer (2002) attribute the limited research concerning the Australian avifauna to a combination of a small number of Australian ornithologists and logistical difficulties of working with species in remote locations. The uniqueness of Australian mammals and the relative ease of capturing sedentary and robust mammal species compared to highly mobile and often nomadic birds means that mammalian research competes favourably for the attention of the limited number of Australian ecophysiologists interested in endotherms. The paucity of endocrinological research for Australian birds is unfortunate; Australian passerines have a historically Gondwanan origin and a high degree of endemism, meaning that they are probably less derived than the avifauna of North America, Europe and Asia and are phylogenetically distinct from convergent northern hemisphere groups (Cracraft et al. 2004). Australian desert birds are therefore likely to provide important information concerning the evolution of environmentally-adaptive traits (Astheimer and Buttemer 2002).

Two major areas of ecophysiological research have attracted some interest for Australian birds. The first is flexible reproduction, where investigators have examined environmental correlates of avian reproductive and life history parameters. Much of this work has focussed on the zebra finch (Taeniopygia formally Poephila guttata), which has become an iconic model of a desert-adapted Australian passerine with a flexible reproductive strategy (Astheimer and Buttemer 2002). Knowledge concerning the endocrinology of Australian desert birds appears to be primarily limited to this particular research area, with investigators concerned with the correlation of reproductive hormone levels with environmental conditions, reproductive phase and behaviour (e.g. Blache et al. 2001; Buttemer and Astheimer 2000; Malecki et al. 1998; McDonald et al. 2001; Vleck and Priedkalns 1985). Likewise, the majority of research concerning osmoregulatory hormones for Australian birds has centred around the idea of flexible reproduction, examining the role of these hormones in reproductive biology, and highlights the importance of water availability and hydration state on reproductive flexibility. Photoperiod is the predominant cue for commencement of breeding for most birds globally, but for southern hemisphere birds, and particularly Australian central and western desert species, various cues related to rainfall and water availability trigger reproduction, and this appears to be mediated by osmoregulatory hormones (Bentley 2002). For example, zebra finches infused with AVT were less aggressive than those infused with the antagonist anti-vasopressin (Goodson and Adkins-Regan 1999), 
and courtship behaviour was suppressed by AVT treatment, probably via suppression of androgen secretion (Harding and Rowe 2003). Therefore the endocrinology of osmoregulation is the mechanism proposed to align reproduction with periods of environmental water availability in environments where resource availability is not necessarily seasonally predictable.

The second area of ecophysioloigcal interest for Australia's avifauna concerns potential physiological adaptations to extreme arid environments. Birds face particular challenges in dry, hot desert environments. Maintaining water balance can be problematic as rates of massspecific water loss are higher for birds than for reptiles and mammals, and thermoregulation is an issue as birds are relatively small and generally diurnally active with the potential for high rates of heat gain from solar radiation and excessive air temperatures (Withers et al. 2004). Various characteristics of birds may pre-adapt them to desert conditions, but there is also evidence that desert birds do indeed have physiological characteristics that may be considered adaptions for persistence in desert environments (Williams and Tieleman 2001).

The galah (Eolophus formally Cacatua roseicapilla) is a small cockatoo that inhabits a large proportion of arid Australia and is the only native Australian desert bird for which the endocrinology of osmoregulation has been examined in any detail. Plasma AVT concentrations of $6.7 \mathrm{pg} \mathrm{ml}^{-1}$ for fully hydrated galahs (Roberts 1991a) were at the lower end of the typical range of 5-20 $\mathrm{pg} \mathrm{ml}^{-1}$ for birds (Goldstein 2006). Five days of water deprivation resulted in a decrease in body mass and an increase in plasma osmolality and haematocrit, along with a 2.6-fold increase in plasma AVT levels that mediated the expected reduction in glomerular flow rate and contributed to renal water conservation (Roberts 1991a). This magnitude of increase with dehydration was also at the lower end of the typical range for birds of 2-6 fold (Goldstein 2006). The sensitivity of the increase in AVT in response to increased plasma osmolarity of galahs was low $\left(0.16 \pm 0.02 \mathrm{pg} \mathrm{ml}^{-1} \mathrm{mOsm}^{-1} \mathrm{~kg}^{-1}\right)$ compared to other birds, which is surprising for an arid-habitat species but may reflect the galah's high tolerance of increased plasma osmolarity, up to $400 \mathrm{mOsm} \mathrm{kg}^{-1}$, or increased kidney sensitivity to AVT (Roberts 1991a; Bentley 2002).

Roberts (1991b) examined the interaction of both osmotic and volemic stimuli on AVT secretion for chickens (Gallus gallus) descended from a feral population living on a Queensland coral atoll with limited water availability, and the potential for environmental 
adaptation of AVT-mediated water conservation. Dehydration of these feral chickens resulted in a decrease in body mass and increase in blood osmolality, accompanied by a 2.8 times increase in AVT and a $62 \%$ decrease in glomerular filtration rate, as expected. However, these arid-adapted chickens had a high sensitivity for AVT release, of $1.75 \pm 0.07 \mathrm{pg} \mathrm{mL}^{-1}$ $\mathrm{mOsm}^{-1}$, compared to domestic strains of chicken $\left(0.5\right.$ to $\left.1.3 \mathrm{pg} \mathrm{mL}^{-1} \mathrm{mOsm}^{-1}\right)$, presumably reflecting adaptation to conditions where water availability is limited (Roberts 1991b). Hypertonic saline infusion also increased AVT secretion, but the sensitivity of release was lower $\left(0.69 \pm 0.11 \mathrm{pg} \mathrm{mL}^{-1} \mathrm{mOsm}^{-1}\right)$ for saline-infused compared to dehydrated birds, despite both treatments resulting in an increased plasma osmolarity (Roberts 1992). This difference was attributed to changes in the extracellular fluid volume; for dehydrated birds, their reduced extracellular fluid volume would stimulate AVT release, but for saline-infused chickens, their increased extracellular fluid volume would suppress AVT release (Roberts 1991b). This study is of particular importance as maintenance of enhanced water conservation ability by feral chicken descendants maintained in a mesic environment for four to five generations (Roberts 1991b, 1992) is strong evidence of genetic adaptation of the endocrine system to environments where water limitation poses a strong selection pressure. This common garden approach has the advantage over in situ field studies in distinguishing genetic adaption from potential environmental or developmental plasticity.

The approach taken for these avian studies, of using AVT sensitivity, calculated as plasma AVT per plasma $\mathrm{mOsm}^{-1}$, as a comparative measure of a species' AVT response to desiccation, has the potential to be more widely applied for comparative studies of endocrinological adaption to aridity, as it may provide a useful standardised comparison between species (e.g. Gray and Simon 1983). However, current interpretation of AVT sensitivity in quantifying avian adaption to aridity is problematic. There is no significant relationship between habitat and AVT sensitivity (one-way ANOVA, $F_{2,7}=0.253, p=0.783$ ) for 10 bird species (data from Bentley 2002 and Chaturvedi et al. 2000; Figure 3). Indeed, opposing patterns of AVT sensitivity have been related to adaption to habitat aridity. For example, galahs have a low AVT sensitivity, interpreted as an adaptation to aridity together with a high tolerance of increased osmolality (Roberts 1991a). However for feral chickens, a high AVT sensitivity was interpreted as an arid adaption, ensuring that a timely decrease in glomerular filtration rate resulted in maximal water conservation (Roberts 1991b). Differences in AVT sensitivity between males and females (e.g. Chaturvedi et al. 2000) may also confound interpretation of this metric, particularly for small datasets. This concept of 
AVT sensitivity would clearly benefit from a broader context; comparison between more species from a wider aridity gradient in a phylogenetic context would be informative and may lead to the development of a useful comparative standard for avain AVT function.

\section{Mammals}

Mammals are a widely-studied taxon, due primarily to their use as models for human medical research, but also to their role as companion and agricultural species, and to their charismatic appeal to biologists. Mammals also have complex thermoregulatory and osmoregulatory homeostatic systems; they have a wider range and extent of thermoregulatory strategies than any other group of tetrapods, even compared with the other major endothermic group, birds. The mammalian kidney is capable of producing much more concentrated urine compared to the avian kidney, and no other tetrapod groups can produce urine above plasma concentration. Therefore, the sophisticated endocrinological control systems required for these mammalian systems are worthy of detailed investigation. The Australian mammal fauna is of particular interest as it is in Australia that all three classes of mammal, the monotremes, marsupials and placentals, are most diverse and readily available for study. The differing evolutionary histories and patterns of radiation of Australian mammals into arid and semiarid regions provides unique opportunities to examine evolutionary, developmental and acclimatory aspects of the endocrinology of osmoregulation and thermoregulation. However, Australian mammalian endocrinological research is unfortunately surprisingly limited, even more so for desert fauna, so there is considerable scope for further research.

\section{Osmoregulation}

Placental mammals have substituted the chemically similar arginine vasopressin (AVP) for AVT as their major osmoregulatory hormone, while lysopressin is presumably the major osmoreguatory hormone for marsupial mammals (Chauvet et al 1980), although the additional pressor homone phenypressin may also be potentially important for marsupials. Much of the early work examining the relationship between water availability and mammalian antidiuretic hormones for desert mammals focussed on North American rodents and their AVP response to dehydration. Weaver et al. (1994) extended this research to the spinifex hopping mouse (Notomys alexis), an Australian desert species for which endocrine control of the renal system would be expected to be particularly well developed, considering their ability to produce the most concentrated urine measured for any mammal; up to 9370 mOsm (MacMillen and Lee 1967). Significant changes in body weight, haematocrit, 
juxtaglomerular cell morphological activity and AVP were observed after seven days of water deprivation then returned to water replete levels with continuing water deprivation; by the end of a 28 day period of water deprivation there was no difference in these variables for water deprived and control animals. It appears that hopping mice require a week to acclimate to chronic water deprivation, but after this period they re-adjust their osmotic balance and as their plasma osmolarity and water volume return to normal they no longer stimulate vasopressin and natriuretic peptide responses. This finding, for the mammalian species with the most extreme urinary concentrating ability, adds strong support to the general consensus that desert rodents do not rely on increased AVP to survive chronic water deprivation, despite desert species having overall higher AVP levels than non-desert species (Heimeier et al. 2004; Heimeier and Donald 2006; Weaver et al. 1994).

The natriuretic peptide system also contributes to osmotic regulation in mammals, acting on target organs including the kidney and vascular smooth muscle to oppose the actions of AVP by stimulating natriuresis, diuresis and vasodilation. There are several forms of NPs in mammals, including atrial, brain and type C NPs. Three forms of cell surface receptors, NP receptor-A, NPR-B and NPR-C, have been recognised, two of which (NPR-A and NPR-B) utilise the secondary messenger cGMP to mediate the action of NPs, via guanylyl cyclase activity (Heimeier and Donald 2006; Heimeier et al. 2002, 2004). In the absence of a clear role for AVP in allowing spinifex hopping mice to survive chronic water deprivation, Heimeier et al. $(2002,2004)$ examined the response of the NP system of water-deprived hopping mice to determine if this antagonistic endocrine system contributed to their renal response. They found that renal atrial NP played a more important role than cardiac atrial NP in the hopping mouse water deprivation response, with no effect of water deprivation on atrial NP mRNA receptors in the heart, but significant changes in the kidney (Heimeier et al. 2002). These effects varied with the period of water deprivation; atrial NP mRNA and guanylyl cyclase mRNA increased in the kidney after seven days of water deprivation and atrial NP mRNA decreased after 14 days while guanylyl cyclase mRNA returned to control levels (Heimeir et al. 2002, 2004). A more comprehensive analysis of the NP system of hopping mice examined plasma levels of atrial and c-type NPs, mRNA expression of both these NPs and the three receptors, and renal NP receptor guanylyl cyclase activity, for water deprivation periods of three, seven, 14 and 28 days (Heimeier et al. 2004). There was no uniform down-regulation of these factors during the experimental period, as might be expected for water conservation. Indeed, after seven and 14 days of water deprivation there 
was an increase in atrial NP stimulated cGMP production, opposite to the expected response. After 28 days most variables were similar to those of control individuals. It therefore appears that a decrease in NP activity is not an important aspect of the physiological response of spinifex hopping mice to chronic water deprivation and our understanding of the endocrinological contribution to osmotic regulation of desert rodents remains limited, despite these species being iconic elements of arid fauna worldwide.

Measurement of AVP and other endocrine contributors to osmoregulatory balance for wild, free-living desert rodents under varying conditions of aridity in Australia and elsewhere is the next step required to understand the control of water balance of desert rodents, but as far as I am aware these studies have not yet been conducted. Australia is home to a suite of native rodents inhabiting a wide aridity gradient facilitating such a comparative study, however with the exception of a few iconic species, their physiology has been largely ignored. Bradshaw (2007) suggested that perhaps wild desert rodents rarely experience the levels of water deprivation anticipated from their renal structure and function, based on measured rates of field water turnover. Therefore, their endocrinology may reflect a lesser requirement for water conservation than generally expected. Such field studies for this iconic group of desert mammals would also provide comparative data for the currently-available field data for Australian desert macropod marsupials.

Australian monotremes provide a potentially unique opportunity to assess evolutionary aspects of the mammalian endocrine system, due to their phylogenetic position as basal mammals. However, most data are available for the short-beaked echidna (Tachyglossus aculeatus) with some additional data for the platypus (Ornithorhynchus anatinus) and the specialised and disparate biology of these species makes generalisation about the early mammalian condition difficult. Echidnas and platypus have low levels of the placental mammal antidiuretic hormone AVP in the pituitary (Sawyer et al. 1960; Chauvet et al. 1985), and reduce urine volume and increase urine concentration in response to dehydration by decreased glomerular filtration and tubular water reabsorption, but no direct link between AVT and kidney function has yet been established (Bentley and Schmidt-Nielsen 1967; Bentley 2002). Clearly, however, AVP rather than the AVT of other tetrapods was established in the mammalian lineage before the divergence of monotremes from other therian mammals. However, marsupials have a diversity of neurohypophysial hormones including AVP, lysine vasopressin (LVP), and in macropods also phenypressin, that 
apparently occur as a consequence of gene duplication (Chauvet et al. 1983a\&b; Hurpet et al. 1980; Rouille et al 1988). Therefore, marsupials have a variety of antidiuretic hormones available, all of which appear to have significant antidiuretic activity (Bentley 2002). Work with quokkas (Setonix brachyurus) and tammar wallabies (Macropus eugenii), small macropod wallabies that are particularly plentiful on seasonally dry islands off the coast of Perth, in Western Australia, demonstrate that kidney function in marsupials is regulated by antidiuretic hormones arising from the hypophysial tract, as for placental mammals, and that the marsupial potential for endocrine regulation of urinary function is comparable to that of placental mammals (Bentley 2002). This, together with considerable evidence from thermoregulatory physiology (e.g. Dawson and Hulbert 1970; Dawson 1983; Dawson 1989), provides further support for the current position that marsupials are not physiologically primitive compared with placental mammals, and that their phylogenetic position as a sister group to placental mammals has resulted in some physiological differences that can not necessarily be considered inferior to those of placental mammals.

Work on arid-habitat Australian marsupials pioneered the measurement of antidiuretic hormones for wild, free-living mammals (Bradshaw 2007). Jones et al. (1990) examined water and osmolyte balance, and measured plasma LVP for the quokka on Rottnest Island where quokkas experience seasonally arid conditions. Most individuals on the island survive without access to drinking water during summer and only those with home ranges near the salt lakes in the centre of the island have access to brackish drinking water (Bradshaw 2007). During mid-summer, quokkas on the west end of the island with no drinking water had significantly higher plasma LVP levels of $89.2 \pm 19.6 \mathrm{pg} \mathrm{ml}^{-1}$ compared to those near the lakes with access to brackish drinking water that had plasma LVP levels of $35.6 \pm 15.8 \mathrm{pg}$ $\mathrm{ml}^{-1}$. Body condition and total body water contents were higher for quokkas near the lakes, and these individuals also had higher rates of water and sodium turnover and lower plasma and urinary osmolalites compared to quokkas on the waterless west end of the island (Jones et al. 1990). Quokkas subsisting in an arid waterless habitat showed evidence of dehydration and their lower water turnover rates were mediated by the effects of elevated plasma LVP. However, when available, quokkas utilised brackish water to improve their water balance and overall body condition, despite a resulting osmotic diuresis from ingesting salty water (Bradshaw 2007; Jones et al 1990). 
A series of interrelated studies examining the osmoregulation of arid-zone macropods in northwest Australia by S.D. Bradshaw and his colleagues has highlighted a range of regulatory responses within this group, that the authors interpreted as regulatory strategies ranging from reliance on endocrine control of the renal system to conserve water during dry periods, to behavioural exploitation of suitable microclimates and an absence of endocrinemediated water conservation (King and Bradshaw 2008). King and Bradshaw (2010) examined the osmoregualtory homeostasis of the Barrow Island euro (Macropus robustus isabellinus), a dwarf subspecies of arid-zone kangaroo restricted to an arid, waterless island off the Pilbara coast of Western Australia. Barrow Island euros were able to maintain osmotic homeostasis their an extremely arid environment, with the exception of a record dry year where there was no rainfall for eight months. Under normal conditions, their low water influx was balanced by an equally low water efflux of only $5.5 \%$ of total body water turnover per day, similar to mainland euros (Macropus robustus erubescens). Significant negative correlations between LVP and total body water content and body condition index suggest that endocrine control of renal water conservation plays an important role in maintaining this water balance. During the drought year, significant increases in plasma LVP, osmolality and cortisol, together with reduced eosinophil counts suggest dehydration; however euros maintained body condition, indicating a remarkable ability for physiological homeostasis under extreme environmental conditions (King and Bradshaw 2010).

The osmoregulatory responses of two arid habitat macropods, the spectacled hare-wallaby and Rothschild's rock-wallaby (Petrogale rothschildi), were compared during periods of environmental water deprivation in the arid Pilbara region of Western Australia (Bradshaw et al. 2001). Hare-wallabies maintained osmotic homeostasis during chronic water shortage and extreme ambient temperatures; temperatures within their spinifex (Triodia angusta) shelters periodically reached $45^{\circ} \mathrm{C}$ during the study. They achieved this with a frugal water use of only $27.5 \mathrm{ml} \mathrm{kg}^{-0.82} \mathrm{day}^{-1}$, the lowest recorded for any mammal. This extreme water economy was mediated by LVP; plasma concentrations of LVP significantly correlated with urine osmotic concentration, increasing from $10.7 \mathrm{pg} \mathrm{ml}^{-1}$ during the wet season to $32.7 \mathrm{pg} \mathrm{ml}^{-1}$ in the dry season. Blood flow to the kidney and glomerular filtration were reduced and filtrate fractional reabsorption increased during the dry period, reducing urine flow rates from 50.2 $\mathrm{ml} \mathrm{kg} \mathrm{d}^{-1}$ to $6.9 \mathrm{ml} \mathrm{kg}^{-1} \mathrm{~d}^{-1}$ and increasing the urine to plasma ratio of osmolytes from 2.0 to 8.4. Rock-wallabies had a higher mass-specific water influx of $64.8 \mathrm{ml} \mathrm{kg}^{-0.82} \mathrm{day}^{-1}$ and much more variable plasma osmotic concentration, total body water content and body condition 
than the hare-wallabies. During the dry season, their urine flow rates decreased, approximating that of the hare-wallabies $\left(6.7 \mathrm{ml} \mathrm{kg}^{-1} \mathrm{~d}^{-1}\right)$, but there was no change in the fractional reabsorption of filtrate, resulting in the ratio of urine to plasma osmolytes remaining at 5.4 in both seasons. Remarkably, there was no correlation between plasma LVP and plasma osmotic concentration, and no seasonal change in LVP consistent with the observed anti-diuresis. The authors suggested that this means that either LVP is not the major anti-diuretic hormone in rock wallabies, or that they lack endocrine control of their renal system. Their behavioural adaptation of sheltering in rock caves with a more favourable microclimate than spinifex bushes may mean that physiological regulation of a stable milieu intérieur is not a pre-requisite for survival in their arid habitat. If this is the case, then limited physiological capacity for osmoregulation means rock wallabies may be vulnerable to environmental change (Bradshaw 2007; Bradshaw et al. 2001).

King and Bradshaw (2008) conducted a more comprehensive study of endocrine versus behaviour mediated osmoregualtory strategies by investigating osmoregulation of four species of Barrow Island macropod over a period of seven years. They obtained data for water turnover, urine and plasma osmolality, plasma LVP concentration and microhabitat conditions for the Barrow Island euro, spectacled hare-wallaby, black-footed rock wallaby (Petrogale lateralis) and the burrowing bettong (Bettongia lesueur) during both wet and dry years, including the driest year on record for Barrow Island, which received only $17.6 \%$ of its annual rainfall and remained dry for eight months (Figure 4). Euros and hare-wallabies experienced a significant increase in both their plasma osmolality, to 106 and $102 \%$ of that of other dry seasons respectively, and LVP, to $16.7 \pm 4.6 \mathrm{pg} \mathrm{ml}^{-1}$ and $20.25 \pm 5.1 \mathrm{pg} \mathrm{ml}^{-1}$ respectively, during this record dry year, but there was no such increase observed for rockwallabies or bettongs; plasma osmolality remained at $271.8 \pm 9.6 \mathrm{mOsm}$ and $277.2 \pm 4.8$ mOsm respectively and LVP remained below the detectable limit of $0.41 \mathrm{pg} \mathrm{ml}^{-1}$ for these two species. It seems that the behavioural strategies of both the rock wallaby and the bettong of exploiting favourable microclimates in rock caves or subterranean warrens confer homeostatic advantages over physiological maintenance of osmotic balance. The blackfooted rock wallaby, like Rothschild's rock-wallaby, showed no evidence of endocrine control of its renal system. Euros and hare-wallabies however appeared to require hormonal control of renal water loss to survive their harsh arid environment in the absence of daytime refugia that buffer the ambient thermal and hygric environment (King and Bradshaw 2008). Controlled laboratory studies, particularly for rock wallabies and bettongs, that negate their 
ability to behaviourally mitigate environmental stressors, may be necessary to definitively delineate differences in hormonal control of osmotic balance.

Quokkas were the subject of the very first studies of endocrinological regulation of sodium and potassium for Australian marsupials. Generally for mammals aldosterone is the predominate adreanal mineralocorticoid, although cortisol and corticosterone can also play a role in salt regulation. Buttle et al. (1952) demonstrated that adrenalectomy of quokkas was fatal within 36 hours, resulting in a reduction in plasma sodium and glucose, an increase in potassium, and variable chloride concentrations. Access to $1 \%$ saline drinking water and injections of whole cortical extract, and the corticosteroid deoxycorticosterone acetate extended survival time. McDonald and Bradshaw (1993) extended this work by demonstrating that adrenalectomised quokkas could survive indefinitely if cortisol and aldosterone were administered; plasma sodium concentration, renal plasma flow and the glomerular filtration rate, along with glucose levels and feeding rates, were maintained in treated animals, but fell in the absence of cortisol and aldosterone injections. McDonald (1974) found similar responses for the arid-habitat red kangaroo (Macropus formally Megaleia rufa) to adrenalectomy; in the absence of steroid injections, plasma sodium and glucose fell, potassium increased and animals stopped feeding, became weak and listless and drank saline water. Injection of cortisol and aldosterone reversed these effects. These responses are similar to those observed for placental mammals and, despite some early work on the Virginia opossum (Didelphis virginiana) that suggested that marsupials do not rely on their adrenal glands to regulate sodium and potassium (Bentley 2002), indicate that an important minerocorticord function of the adrenal glands is shared by both marsupial and placental mammals. This minerocorticord role is however unlikely for monotremes. Monotreme adrenal glands do not have a distinct division into a cortex and medulla and although the platypus adrenal is similar in form to that of other mammals, in the echidna it is small and more similar in structure to that of a reptile (Griffiths 1989). Corticosterone is the major adrenal hormone of echidnas, although cortisol is predominate in the platypus, but it occurs at low concentrations and appears to have a limited mineralcorticoid role; unstressed adrenaectomised echidnas can survive for at least 20 weeks, a unique situation amongst mammals (McDonald and Augee 1968; Weiss and McDonald 1965). However, it is unclear if this is a primitive or derived trait for these basal mammals. Considerable further work on the endocrinology of monotremes is required to fully exploit their unique positon as basal mammals and draw firm conclusions concerning the evolution of the mammalian 
osmoregulatory endocrine response. In addition, short-beaked echidnas have a ubiquitous distribution throughout Australia encompassing all available climatic zones; they have the widest distribution of any Australian mammal. Examining potential variation in their endocrinology with respect to water balance and thermoregulation throughout their geographic range would be informative regarding the plasticity and potential for adaption of the mammalian endocrine system; this is a fruitful topic for future investigation.

Captive quokkas deprived of salt significantly increased their plasma concentration of aldosterone, from baseline levels of $2.33 \pm 0.57 \mathrm{ng} 100 \mathrm{ml}^{-1}$ to $16.95 \pm 2.74 \mathrm{ng} 100 \mathrm{ml}^{-1}$ when salt-deprived (Miller and Bradshaw 1979). There was no effect of dietary sodium content on total plasma corticosteroid levels. Plasma aldosterone levels for quokkas on Rottnest Island did not differ between the hot, dry summer months and the cooler, wetter winter months, suggesting that they obtain sufficient salt in their diet year-round, with the possible exception of mid-winter (July). However, body condition and cortisol levels varied significantly throughout the year, and suggested that quokkas were under some physiological stress during the cooler months (Miller and Bradshaw 1979). Comparison of quokkas inhabiting central and coastal locations on Rottnest Island found that quokkas near the coast had much lower aldosterone concentrations, and higher urine osmolality that central quokkas, presumably as prevailing winds covered the coastal vegetation with salt spray and therefore increased the sodium content of coastal quokka diets (Bradshaw 1983).

\section{Thermoregulation}

The unique reproductive strategy of marsupials, where extremely altricial young are born after a very short gestation period, completing much of their development during lactation, together with an array of physiological thermoregulatory strategies (hibernation, torpor and homeothermy) for survival in harsh desert environments, means that there is much scope for comparative and experimental study of the endocrinology of thermoregulation for Australian desert fauna. However, there is a surprising paucity of data on this topic. For example, Richardson (2008) reviewed the use of marsupials as a model for investigating the evolution of thyroid hormone distributor proteins, and concluded that study of marsupials has contributed to identification of possible selection pressures driving evolution of the hepatic gene expression of transthyretin, in a broad evolutionary context. However, she recognised that marsupials, despite their great potential to shed light on developmental and evolutionary studies of endocrinology, are under-exploited as a group. 
The thyroid gland as well as other organs including the kidney, skeletal muscle and liver produce a number of hormones with various patterns of iodination (e.g. $T_{2}, T_{3}, T_{4}$ ) collectively known as thyroid hormones. For endotherms such as mammals, thyroid hormones play an important role in the regulation of basal metabolic rate (BMR), and therefore rates of basal heat production or obligatory thermogenesis. Increasing or decreasing thyroid hormone input can change BMR by about 50\% (Somogyi et al. 2011). The majority of the work examining thyroid hormone function in Australian marsupials has involved mesic species such as the tammar wallaby, Tasmanian bettong (Bettongia gaimardi), potoroo (Potorous tridactylus), northern brown bandicoot (Isoodon macrourus) and brushtail possum (Trichosurus vulpecula; e.g. Gemmell and Sernia 1992; Janssens et al. 1990; Nicol 1977; Richardson et al. 2002; Rose and Kuswanti 2004; Setchell 1974, Sernia et al. 1997), presumably due to their ready availability near major research institutions, which are generally situated in coastal cities, and contribute little knowledge concerning adaptation to desert environments. However, Richardson et al. (2005) included the arid-habitat fat-tailed dunnart (Sminthopsis crassicaudata) in their study of the evolution of thyroxine-binding plasma proteins, and were the first to determine that an Australian polyprotodont marsupial synthesises transthyretin (one of three thyroid hormone distributor proteins that assist in the transport of thyroid hormones to the sites of action via the bloodstream) in its liver during development, in addition to thyroxine-binding globulin already identified in diprotodont pouch young. This synthesis ceased in independent individuals (at the stage when diprotodonts develop a functional thyroid gland and become endothermic), but it is unknown if dunnarts have a functional thyroid gland as adults; plasma thyroid hormones have not been measured for this species, and adults remain heterothermic (Richardson et al 2005). Therefore, further investigation concerning the development of thyroid function in this and other desert heterothermic marsupials is warranted.

Dunnarts have been the subject of other studies of endocrine impacts on thermoregulation, due to their propensity to enter daily torpor. Geiser et al. (1998) examined the effect of leptin on daily torpor for the stripe-faced dunnart, Sminthopsis macroura. Leptin is a cytokine peptide hormone derived primarily from white adipose tissue, but also other tissues including BAT, stomach epithelial cells, liver, heart and skeletal muscle. Leptin is well-known for its role in regulating food intake and body mass, but it also has important roles in metabolic and thermal regulatory processes (Ahima and Flier 2000; Szekely et al. 2010). For S. macroura, 
four days of administration of leptin once daily resulted in a 50\% decrease in the duration of torpor bouts, an increase in daily minimum $\mathrm{T}_{\mathrm{b}}$ of $4.5^{\circ} \mathrm{C}$ and a 2.2 fold increase in the daily minimum metabolic rate. Overall daily expenditure increased by $9 \%$ during treatment with leptin compared to control periods. Neither maximum $\mathrm{T}_{\mathrm{b}}$ and metabolic rate nor average active phase $T_{b}$ and metabolic rate were significantly influenced by leptin. Body mass was also not influenced by leptin during the four day study period. These findings indicate that leptin results in an increase in rest phase energy expenditure, resulting from decreased torpor depth and duration, of a marsupial. Similarities between this marsupial's response to leptin and that of phylogenetically distant rats and mice suggest that leptin has an ancient thermoregulatory function. The absence of BAT in marsupials also indicates that functional BAT is not necessary for leptin to have a physiological impact on energy expenditure. The mode of action of leptin in dunnarts remains unclear, but Geiser et al. (1998) suggest that it may function by increasing the $T_{b}$ set point during torpor rather than directly affecting energy expenditure.

Although the osmoregulatory function of the adrenal gland of the short-beaked echidna appears to differ from that of other mammals, its thermoregulatory role is similar. Corticosteroids have metabolic effects that influence thermoregulation, and in general adrenalectomised mammals show impaired thermoregulatory function at low ambient temperatures. Adreanalectomised echidnas are also unable to thermoregulate at low ambient temperatures, although cortisol injection or glucose perfusion allows these individuals to maintain a normothermic $\mathrm{T}_{\mathrm{b}}$, suggesting that glucocorticoids in these monotremes function to stimulate gluconeogenesis under stressful environmental conditions (Augee and McDonald 1973), as for other mammals.

Reproductive hormones such as testosterone, progesterone and oestrogen can also impact on thermoregulation, generally to maintain $\mathrm{T}_{\mathrm{b}}$ in an optimal range for gamete and embryo development. The effect of reproductive hormones on the thermoregulation has been examined for two species of dunnart, the fat-tailed dunnart (Hope et al. 2000) and the striped faced dunnart (McAllan et al. 2012). For fat-tailed dunnarts, ovariectomy, and therefore an absence of ovarian steroids, resulted in both an increase in body fat mass and a decrease in the expression of uncoupling protein 2 (UCP2) mRNA expression in skeletal muscle and sometimes adipose tissue for fat-tailed dunnarts. These responses were mediated by photoperiod; animals exposed to short day lengths had greater increase in fat mass, and only 
animals exposed to short-day length decreased expression of UCP2 mRNA expression in adipose tissue (Hope et al. 2000). For stripe-faced dunnarts, testosterone increased body mass and fattening (tail width) of males, and although it did not affect resting metabolic rate and the frequency of torpor use, testosterone did reduce torpor bout duration for animals exposed to short photoperiods. For females, there was no effect on body mass of the reproductive hormones oestrogen or progesterone, but progesterone did increase fattening under short photoperiods. Progesterone, but not oestrogen, reduced torpor frequency and bout duration for females exposed to long photoperiods, but not for those exposed to short photoperiods. Torpor metabolic rate was not influenced by hormones or photoperiod for either males or females (McAllan et al. 2012). These studies indicate that thermoregulatory impacts of reproductive hormones for these arid-habitat dasyurid marsupials are strongly mediated by photoperiod, which is presumably an important cue to align reproduction to the most favourable time of the year (winter). Importantly, circulating reproductive hormones do not eliminate torpor use, as occurs in many seasonally hibernating placental mammals. Torpor is an important factor in the survival of dunnarts in their arid habitat, where food availability is unpredictable and temperatures can be extreme. Therefore the ability to use torpor during reproductive periods enhances energy conservation while still enabling reproduction to occur (McAllan et al. 2012).

\section{Conclusions}

The study of Australian desert tetrapods has contributed greatly to our understanding of the role of the endocrine system as a control mechanism for both osmoregulation and thermoregulation, particularly for reptiles and marsupial mammals. The extreme temperature and unpredictability of water availability in Australian deserts means that tetrapods inhabiting these environments require appropriate homeostatic control mechanisms to maintain a suitable milieu intérieur for optimal biological functioning. In most cases, the endocrine system is an essential element of these control mechanisms, although in some situations (e.g. osmoregulation during dehydration for desert rock wallabies, burrowing bettongs and spinifex hopping mice) other physiological and/or behavioural mechanisms are also very important and may even negate the requirement for some aspects of hormonal control.

Studies of Australian desert fauna have often been at the forefront of determining the role and mechanism of action of particular hormone systems (e.g. squamates and AVT) with researchers studying Australian fauna pioneering work on the function of the endocrine 
system with respect to both osmoregulation and thermoregulation. However, it has been the study of endocrine function for wild, free-living amphibians, reptiles and mammals, particularly osmoregulatory endocrinology, where Australian faunal studies have made the greatest contribution to the discipline. Field studies conducted in Australia's arid zone have revealed the function of the endocrine system in response to natural environmental conditions, and enabled researchers to understand the response of species to potential environmental stressors in their natural habitats. In many cases these field studies were the first and remain the only data for field endocrinology of particular taxa. These field studies, when combined with controlled experimental laboratory investigations, provide a complete picture of the endocrine homeostatic system for thermoregulation and osmoregulation.

Despite the importance and contribution of research on the Australian desert fauna, there is considerable scope for further study. Australian endocrinological studies have been limited to relatively few laboratories, and generally reflect the interests and achievements of only a handful of researchers. Although these contributions are impressive, this has necessarily limited the scope of work. The unique evolutionary history of all aspects of the Australian fauna, with various periods of diversification in desert habitats and therefore differing potential for adaption to hot, dry environments, has not been fully exploited. Current studies are too few and too fragmented in a taxonomic and environmental sense to be synthesised into a detailed phylogenetically informed analysis that may shed light on past selection pressures and future potential for adaptive change of endocrine regulatory mechanisms. The fact that research on Australian desert fauna has so often pioneered investigations into osmoregulatory and thermoregulatory endocrinology means that there are few studies of taxa from other regions for robust comparative analyses, and the various elements of the Australian fauna have not been investigated in any systematic way. Although further endocrinological studies for all taxa are desirable, Australian desert birds stand out as the group of Australian tetrapods that require considerable attention, reflecting the overall limited knowledge of Australian avian physiology beyond reproductive physiology, despite the potential to provide new information as to how these small, diurnal endotherms can balance their water budgets and defend a relatively stable $\mathrm{T}_{\mathrm{b}}$ in conditions of extreme heat and aridity. Considering the thermal and osmoregulatory challenges faced by Australian desert birds, there is considerable potential to address interesting questions concerning the role, function and adaptation of the avian endocrine system, in an evolutionary context. 
Understanding the evolutionary and adaptive aspects of the endocrinological control of tetrapods is an area of particular importance for predicting the responses and adaptive potential of species in the face of inevitable human-mediated habitat modification and climate change. This is of particular consequence for Australia's desert fauna, which has already suffered considerable attrition post European settlement and is particularly vulnerable to further desertification due to the difficulties of surviving in areas with already impoverished soils, extreme temperatures and unpredictable rainfall.

\section{Acknowledgements}

I thank Professor Philip Withers and two anonymous reviewers for comments and suggestions on this manuscript. 


\section{References}

Ahima, R.S., Flier, J.S. 2000. Leptin. Ann. Rev. Physiol. 62, 413-437.

Astheimer, L.B., Buttemer, W.A. 2002. Changes in latitude, changes in attitude: A perspective on ecophysiological studies of Australian birds. Emu 102, 19-27.

Augee, M.L., McDonald, I.R. 1973. Role of the adrenal cortex $\mathrm{n}$ the adaptation of the monotreme Tachyglossus aculeatus to low environmental temperature. J. Endocrinol. 58, 513-523.

Bentley, P.J. 1959. Studies on the water and electrolyte metabolism of the lizard Trachydosaurus rugosus (Grey). J. Physiol. (Lond) 145, 37-47.

Bentley, P.J. 2002. Endocrines and Osmoregulation: A Comparative Account in Vertebrates. Springer-Verlag, Berlin.

Bentley, P.J. and Schmidt-Nielsen, K. 1967. The role of the kidney in water balance of the echidna. Comp. Biochem. Physiol. 20, 285-290.

Blache, D., Talbot, R.T., Blackberry, M.A., Williams, K.M., Martin G.B., Sharp P.J. 2001. Photoperiodic control of the concentration of luteinizing hormone, prolactin and testosterone in the male emu (Dromaius novaehollandiae), a bird that breeds on short days. J. Neuroendocrinol. 13, 998-1006.

Bradshaw, S.D. 1970. Seasonal changes in the water and electrolyte metabolism of Amphibolurus lizards in the field. Comp. Biochem. Physiol. 36, 689-717.

Bradshaw, S.D. 1972. The endocrine control of water and electrolyte metabolism in desert reptiles. Gen. Comp. Endocrinol. Supp. 3, 360-373.

Bradshaw, S.D. 1975. Osmoregulation and pituitary-adrenal function in desert reptiles. Gen. Comp. Endocrinol. 25, 230-248.

Bradshaw, S.D. 1976. Effect of hypothalamic lesions on kidney and adrenal function of the lizard Amphibolurus ornatus. Gen. Comp. Endocrinol. 29, 285.

Bradshaw, S.D. 1983. Recent endocrinological research on the Rottnest Island quokka (Setonix brachyurus). J. Royal Soc. West. Aust. 66, 55-61.

Bradshaw, S.D. 1986. Ecophysiology of Desert Reptiles. Academic Press, Sydney.

Bradshaw, S.D., 1992. Ecophysiology of desert reptiles, in Adler, K. (Ed.) Herpetology: Current Research on the Biology of Amphibians and Reptiles. Cornell University, New York, pp 121-130.

Bradshaw, S.D. 1997. Homeostasis in Desert Reptiles. Springer-Verlag, Berlin.

Bradshaw, S.D. 2003. Vertebrate Ecophysiology: An Introduction to its Principles and Applications. Cambridge University Press, Cambridge.

Bradshaw, S.D. 2007. Environmental endocrinology. Gen. Comp. Endocrinol. 152, 125-141.

Bradshaw, F.J., Bradshaw, S.D. 1996. Arginine vasotocin: Locus of action along the nephron of the ornate dragon lizard, Ctenophorus ornatus. Gen. Comp. Endocrinol. 103, 281-289.

Bradshaw, S.D., Bradshaw, F.J. 2002. Arginine vasotocin: Site and mode of action in the reptilian kidney. Gen. Comp. Endocrinol. 126, 7-13.

Bradshaw, S.D., Grenot, C.J. 1976. Plasma aldosterone levels in two reptilian species, Uromastix acanthinurus and Tiliqua rugosa, and the effect of several experimental treatments. J. Comp. Physiol. B. 111, 71-76. 
Bradshaw, S.D., Ladyman, M., Stewart, T. 2007. Effect of hypernatraemia and the neurohypophysial peptide, arginine vasotocin (AVT) on behavioural thermoreguation in the agamid lizard, Ctenophorus ornatus. Gen. Comp. Endocrinol. 150, 34-40.

Bradshaw, S.D., Morris, K.D., Bradshaw, F.J., 2001. Water and electrolyte homeostasis and kidney function of desert-dwelling marsupial wallabies in Western Australia. J. Comp. Physiol. B. 171, 23-32.

Bradshaw, S.D., Rice, G.E. 1981. The effects of pituitary and adrenal hormones on renal and post-renal reabsorption of water and electrolytes in the lizard Varanus gouldii (Gray). Gen. Comp. Endocrinol. 44, 82-93.

Braysher, M.L. 1976. The excretion of hyperosmotic urine and other aspects of the electrolyte balance of the lizard Amphibolurus maculosus. Comp. Biochem. Physiol. A. 54, 341-345.

Buttemer, W.A., Astheimer, L.B. 2000. Testosterone does not affect basal metabolic rate or blood parasite load in captive male white-plumed honeyeaters Lichenostomus penicillatus. J. Avian Biol. 31, 479-488.

Buttemer W.A., Thomas, C. 2003. Influence of temperature on evaporative water loss and cutaneous resistance to water vapour diffusion in the orange-thighed frog Litoria xanthomera. Aust. J. Zool. 51, 111-118.

Buttle, J., Kirk, R.L., Waring, H. 1952. The effect of complete adrenalectomy on the wallaby (Setonyx brachyurus). J. Endocrinol. 8, 281-290.

Cartledge, V.A., Withers, P.C., Bradshaw, S.D. 2008. Water balance and arginine vasotocin in the cocooning frog Cyclorana platycephala (Hylidae). Physiol. Biochem. Zool. 81, 43-53.

Cartledge, V.A., Withers, P.C., McMaster, K.A., Thompson, G.G., Bradshaw, S.D. 2006a. Water balance of field-excavated aestivating Australian desert frogs, the cocoon-forming Neobatrachus aquilonius and the non-cocooning Notaden nichollsi (Amphibia: Myobatrachidae). J. Exp. Biol. 209, 3309-3321.

Cartledge, V.A., Withers, P.C., Thompson, G.G., McMaster, K.A. 2006b. Water relations of the burrowing sandhill frog, Arenophryne rotunda (Myobatrachidae). J. Comp. Physiol. B. 176, 295-302.

Chaturvedi, C.M., Chowdhary, A., Wall, P.T., Koike, T.I., Cornett, L.E., 2000. Sexual dimorphism in hypothalamic arginine vasotocin (AVT) gene expression and AVT plasma levels in the Japanese quail (Coturnix coturnix japonica) in response to water deprivation. Gen. Comp. Endocrinol. 117, 129-137.

Chauvet, M.T., Hurpet, D., Chauvet, J., Acher, R. 1980. Phenypressin (Phe2-Arg8vasopressin), a new neuropypohysial peptide found in marsupials. Nature 287, 640-642.

Chauvet, M., Colne, T., Hurpet, D., Chauvet, J., Acher, R. 1983a. A multigene family for the vasopressin-like hormones? Identification of mesotocin, lysipressin and phenypressin in Australian macropods. Biochem. Biophys. Res. Comm. 116, 258-263.

Chauvet, M., Colne, T., Hurpet, D., Chauvet, J., Acher, R. 1983b. Marsupial neurohypophysial hormones: Identification of mesotocin, LVP and phenypressin in the quokka wallaby. Gen. Comp. Endocrinol. 52, 309-315.

Chauvet, J., Hurpet, D., Michel, G., Chauvet, M, Carrick, F.N., Acher, R. 1985 The neurohypophysial hormones of the egg-laying mammals: Identification of arginine 
vasopressin in the platypus (Ornithorhynchus anatinus). Biochem. Biophys. Res. Comm. 127, 277-282.

Cracraft, J., Barker, F.K., Braun, M., Harshmen, J., Dyke, G.J., Feinstein, J., Stanly, S., Cibois, A., Schilder, P., Beresford, P., Garcia-Moreno, J., Sorenson, M.D., Yuri, T., Mindell, D.P. 2004. Phylogenetic relationships among modern birds (Neornithes). Towards an avian tree of life Chapter 27, in: Cracraft, J (Ed.), Assembling the Tree of Life. Oxford University Press, Oxford, pp. 468-489.

Dawson, T.J. 1983. Monotremes and Marsupials: The Other Mammals. Edward Arnold, London.

Dawson, T.J. 1989. Responses to cold of monotremes and marsupials, in Wang, L.C.H (Ed.) Advances in Comparative and Environmental Physiology. Springer-Verlag, Berlin pp. 255-288.

Dawson, T.J., Hulbert, A.J. 1970. Standard metabolism, body temperature and surface areas of Australian marsupials. Am. J. Physiol. 218, 1233-1238.

Donald, J.A., Trajanovska, S. 2006. A perspective on the role of natriuretic peptides in amphibian osmoregulation. Gen. Comp. Endocrinol. 147, 47-53.

Donald, J.A., Meier, S.K., Riddell, S.R. 2002. Toad atrial natriuretic peptide: cDNA cloning and function analysis in isolated perfused kidneys. Physiol. Biochem. Zool. 75, 617-626.

Ellis, D.J., Firth, B.T., Belan, I. 2007. Circadian rhythms of locomotor activity and temperature selection in sleepy lizards, Tiliqua rugosa. J. Comp. Physiol. A. 193, 695701.

Ellis, D.J., Firth, B.T., Belan, I. 2008. Interseasonal variation in the circadian rhythms of locomotor activity and temperature selection in sleepy lizards, Tiliqua rugosa. J. Comp. Physiol. A. 194, 701-712.

Firth, B.T., Belan, I., Dennaway, D.J. 2006. Persistence of a plasma melatonin rhythm in constant darkness and its inhibition by constant light in the sleepy lizard, Tiliqua rugosa. J. Pineal. Res. 41, 15-20.

Firth, B.T., Kennaway, D.J. 1980. Plasma melatonin levels in the scincid lizard Trachydosaurus rugosus. The effects of parietal eye and lateral eye impairment. J. Exp. Biol. 85, 311-321.

Firth, B.T., Kennaway, D.J. 1987. Melatonin content of the pineal, parietal eye and blood plasma of the lizard, Trachydosaurus rugosus: Effect of constant and fluctuating temperature. Brain Res. 404, 313-318.

Firth, B.T., Kennaway, D.J. 1989. Thermoperiod and photoperiod interact to affect the phase of the plasma melatonin rhythm in the lizard, Tiliqua rugosa. Neurosci. Lett. 106, 125130.

Firth, B.T., Kennaway, D.J., Belan, I. 1991. Thermoperiodic influences on plasma melatonin rhythms in the lizard Tiliqua rugosa: Effect of thermophase duration. Neurosci. Lett. 121, 139-142.

Firth, B.T., Kennaway, D.J., Rozenbilds, M.A.M. 1979. Plasma melatonin in the scincid lizard, Trachydosaurus rugosus: Diel rhythm, seasonality, and the effect of constant light and constant darkness. Gen. Comp. Endocrinol. 37, 493-500.

Firth, B.T., Thompson, M.B., Kennaway, D.J., Belan, I. 1989. Thermal sensitivity of reptilian melatonin rhythms: "cold" tuatara vs "warm" skink. Am. J. Physiol. 256, R1160-R1163. 
Ford, S.S., Bradshaw, S.D. 2006. Kidney function and the role of arginine vasotocin in three agamid lizards from habitats of differing aridity in Western Australia. Gen. Comp. Endocrinol. 147, 62-69.

Fraser, S.P. 1985. Variability of heating and cooling rates during radiant heating in a scincid lizard, Egernia cunninghami. Comp. Biochem. Physiol. 57, 392-400.

Geiser F., Körtner, G.,Schmidt, I. 1998. Leptin increases energy expenditure of a marsupial by inhibition of daily torpor. Am. J. Physiol. 275, R1627-R1632.

Geen, M.R.S., Johnston, G.R. 2014. Coloration affects heating and cooling in three colour morphs of the Australian bluetongue lizard, Tiliqua scincoides. J. Therm. Biol. 43, 5460.

Gemmell, R.T., Sernia, C., 1992. The transfer of thyroxine from the mother to the young of the marsupials, the bandicoot (Isoodon macrourus) and the possum (Trichosurus vulpecula). Comp. Biochem. Physiol. 103, 541-543.

Goldstein, D.L. 2006. Regulation of the avian kidney by arginine vasotocin. Gen. Comp. Endocrinol. 147, 78-84.

Goodson, J.L., Adkins-Regan E. 1999. Effect of intraseptal vasotocin and vasoactive intestinal polypeptide infusions on courtship song and aggression in the male zebra finch. J. Neuroendocrinol. 11, 19-25.

Gray, D.A., Simon, E. 1983. Mammalian and avian antidiuretic homone: Studies related to possible species variation in osmoregulatory systems. J. Comp. Physiol. 151, 241-246.

Griffiths, M. 1989. Tachyglossidae, in Walton, D.W., Richardson, B.J. (Eds.) Fauna of Australia Mammalia Vol 1B. Australian Government Publishing Service, Canberra, pp. 407-435.

Grigg, G., Seebacher, F. 1999. Field test of a paradigm: hysteresis of heart rate in thermoregulation by a free-ranging lizard (Pogona barbata). Proc. Royal. Soc. Lond. B. 266, 1291-1297.

Harding, C.F., Rowe, S.A. 2003. Vasotocin treatment inhibits courtship in male zebra finches; concomitant androgen treatment inhibits this effect. Horm. Beh. 44, 413-418.

Heatwole, H. 1987. Major components and distribution of the terrestrial fauna, in Dyne, G.R., Walton D.W. (eds.) Fauna of Australia. Vol 1 General Articles., Australian Government Publishing Service, Canberra, Pp. 101-135.

Heimeier, R.A., Bartolo, R.C., Donald, J.A. 2004. The effect of water deprivation on signalling molecules that utilise cGMP in the spinifex hopping mouse Notomys alexis. Aust. Mamm. 26: 191-198.

Heimeier, R.A., Davis, B.J., Donald, J.A., 2002. The effect of water deprivation on the expression of atrial natriuretic peptide and its receptors in the spinifex hopping mouse, Notomys alexis. Comp. Biochem. Physiol. A. 132, 893-903.

Heimeier, R.A., Donald, J.A. 2006. The response of the natriuretic peptide system to water deprivation in the desert rodent, Notomys alexis. Comp. Biochem. Physiol. A. 143, 193201.

Hope, P.J., Turnbill, H., Breed, W., Morley, J.E., Horowitz, M., Wittert, G.A. 2000. The effect of ovarian steroid and photoperiod on body fat stores and uncoupling protein 2 in the marsupial Sminthopsis crassicaudata. Physiol. Behav. 69, 463-470. 
Hurpet, D., Chauvet, M.T., Chauvet, J., Acher, R. 1980. Identification of lysine vasopressin in two Australian marsupials, the red kangaroo and the tammar. Biochem. Biophys. Res. Commun. 95, 1585-1590.

Janssens, P.A., Grigg, J.A., Dove, H., Hulbert, A.J. 1990. Thyriod hormones during development of a marsupial, the tammar wallaby, Macropus eugenii. J. Endocrinol. 127, 427-436.

Jones, M.E.E., Bradshaw, S.D., Fergusson, D., Watts, R. 1990. The effect of available surface water on levels of anti-diuretic hormone (lysine vasopressin) and water and electrolyte metabolism of the Rottnest Island quokka (Setonix brachyurus). Gen. Comp. Endocrinol. 77, 75-87.

King, J.M., Bradshaw, S.D. 2008. Comparative water metabolism of Barrow Island macropodid marsupials: Hormonal versus behavioural-dependant mechanisms of body water conservation. Gen. Comp. Endocrinol. 155, 378-385.

King, J.M., Bradshaw, S.D. 2010. Stress in an island kangaroo? The Barrow Island euro, Macropus robustus isabellinus. Gen. Comp. Endocrinol. 167, 60-67.

Konno, N., Hyodo, S., Takei, Y., Matsuda, K. 2005. Plasma aldosterone, angiotensin II, and arginine vasotocin concentrations in the toad, Bufo marinus, following osmotic treatments. Gen. Comp. Endocrinol. 140, 86-93.

Ladyman, M., Bradshaw, S.D. 2003. The influence of dehydration on the thermal preferences of the western tiger snake, Notechis scutatus. J. Comp. Physiol. B. 173, 239-246.

Ladyman, M., Bradshaw, S.D., Bradshaw, F. 2006. Physiological and hormonal control of thermal depression in the tiger snake, Notechis scutatus. J. Comp. Physiol. B. 176, 547557.

Lutterschmidt, D.I., Lutterschmidt, W.I., Hutchison, V.H. 2003. Melatonin and thermoregulation in ecotothermic vertebrates: A review. Can. J. Zool. 81, 1-13.

MacMillen, R.E, Lee, A.K. 1967. Australian desert mice: independence of exogenous water. Science 158, 383-385.

Malecki IA, Martin G.B., O’Malley P.J., Meyer G.T. Talbot R.T., Sharp P.J. 1998. Endocrine and testicular changes in a short-day seasonally breeding bird, the emu Dromaius novaehollandiae, in south-western Australia. Anim. Repro. Sci. 53, 143-155.

Martin, H.A. 2006. Cenozoic climatic change and the development of the arid vegetation in Australia. J. Arid Environ. 66, 533-563.

McAllan, B.M., Feay, N., Bradley, A.J., Geiser, F., 2012. The influence of reproductive hormones on the torpor patterns of the marsupial Sminthopsis macroura: Bet-hedging in an unpredictable environment. Gen. Comp. Endocrinol. 179, 265-276.

McCormick, S.D., Bradshaw, S.D. 2006. Hormonal control of salt and water balance in vertebrates. Gen. Comp. Endocrinol. 147, 3-8.

McDonald, I.R., 1974. Adrenal insufficiency in the red kangaroo (Megaleia rufa Desm). J. Endocrinol. 62, 689-678.

McDonald, I.R., Augee, M.L. 1968. Effects of bilateral adrenalectomy in the monotreme Tachyglossus aculeatus Comp. Biochem. Physiol. 27, 671-678.

McDonald, I.R., Bradshaw, S.D. 1993. Adrenalectomy and steroid replacement in a small macropodid marsupial, the quokka (Setonix brachyurus): Metabolic and renal effects Gen. Comp. Endocrinol. 90, 64-77. 
McDonald P.G., Buttemer, W.A., Astheimer L.B. 2001. The influence of testosterone on territorial defence and parental behaviour in male free-living rufous whistlers, Pachycephala rufiventris. Horm. Behav. 39, 185-194.

McLeod J.L., Donald, J.A. 1999. Relationship between arginine vasotocin-like and natriuretic peptide-like immunoreactive structures in the brain of the toad Bufo marinus. Cell Tiss. Res. 297, 47-55.

McLeod J.L., Donald, J.A. 2000. Atrial natriuretic peptide binding sites in the brain and pituitary gland of the toad, Bufo marinus: Localisation and receptor characterisation. Cell Tiss. Res. 302, 95-104.

Meier, S., Donald, J.A. 2002. Functional analysis of natriuretic peptide receptors in the bladder of the toad Bufo marinus. Gen. Comp. Endocrinol. 125, 207-217.

Meier, S., Toop, T., Donald, J.A. 1999. Distribution and characterization of natriuretic peptide receptors in the kidney of the toad, Bufo marinus. Gen. Comp. Endocrinol. 115, 207-217.

Miller, T., Bradshaw, S.D. 1979. Adrenocortical fuction in a field population of a macropodid marsupial (Setonix brachyurus, Quoy and Gaimard). J. Endocrinol. 82, 159-170.

Minerds, K.L., Donald, J.A. 1997. Lack of evidence for functional natriuretic peptide receptors in the heart of the cane toad, Bufo marinus. Comp. Biochem. Physiol. C. 118, 233-240.

Minerds, K.L., Donald, J.A. 2001. Natriuretic peptide receptors in the central vasculature of the toad, Bufo marinus. Comp. Biochem. Physiol. A. 128, 259-268.

Morton, S.R., Stafford Smith, D.M., Dickman, C.R., Dunkerley, D.L., Friedel, M.H., McAllister, R.R.J., Reid, J.R.W., Roshier, D.A., Smith, M.A., Walsh, F.J., Wardle, G.M., Watson, I.W., Westoby, M. 2011. A fresh framework of the ecology of arid Australia. J. Arid Environ. 75, 313-329.

Moyer, R.W., Firth, B.T., Kennaway, D.J. 1997. Effect of variable temperatures, darkness and light on the secretion of melatonin by pineal explants in the gecko, Christinus marmoratus. Brain Res. 747, 230-235.

Nicol, S.J. 1977. Thyroid function in the potoroo, Potorous tridactylus (Kerr). Aust. J. Zool. $25,419-421$.

Nouwen, E.J., Kühn, E.R. 1983. Radioimmunoassay of arginine vasotocin and mesotocin in serum of the frog Rana ridibunda. Gen. Comp. Endocrinol. 50, 242-251.

Pang, P. 1977. Osmoregulatory functions of neurohypophysial hormones in fishes and amphibians. Am. Zool. 17, 739-749.

Rice, G.E. 1982. Plasma arginine vasotocin concentrations in the lizard Varanus gouldii (Grey) following water loading, salt loading and dehydration. Gen. Comp. Endocrinol. 47, 1-6.

Rice, G.E., Bradshaw, S.D. 1980. Changes in dermal reflectance and vascularity and their effects on thermoregulation in Amphibolurus nuchalis (Reptilia: Agamidae). J. Comp. Physiol. 135, 139-146.

Rice, G.E., Bradshaw, S.D., Prendergast, F.J. 1982. The effects of bilateral adrenalectomy on renal function in the lizard Varanus gouldii (Grey). Gen. Comp. Endocrinol. 47, 182189. 
Richardson, S.J. 2008. Marsupial models for understanding evolution of thyroid hormone distributor proteins. Molec. Cell. Endocrinol. 293, 32-42.

Richardson, S.J., Monk, J.A., Shepherdley, C.A., Ebbesson, L.O.E., Sin, F., Power, D.M., Frappell, P.B., Köhrle, J., Renfree M.B. 2005. Developmentally regulated thyroid hormone distributor proteins in marsupials, a reptile, and fish. Am. J. Physiol. 288, R1264-R1272.

Richardson, S.J., Aldred, A.R., Leng, S.L., Renfree, M.B., Hulbert, A.J., Schreibera, G. 2002. Developmental profile of thyroid hormone distributor proteins in a marsupial, the tammar wallaby Macropus eugenii. Gen. Comp. Endocrinol. 125, 92-103.

Roberts, J. 1991a. Renal function and plasma arginine vasotocin during water deprivation in an Australian parrot, the galah (Cacatua roseicapilla). J. Comp. Physiol. B. 161, 620625 .

Roberts, J. 1991b. Effects of water deprivation on renal function and plasma arginine vasotocin in the feral chicken, Gallus gallus (Phasianidae). Aust. J. Zool. 39, 439-46.

Roberts, J. 1992. Renal function and plasma arginine vasotocin during an acute salt load in feral chickens. J. Comp. Physiol. B. 162, 54-58.

Rose, R.W.,Kuswanti, N. 2004. Thyroid function and the development of endothermy in a marsupial, the Tasmanian bettong, Bettongia gaimardi (Demarest 1822). Gen. Comp. Endocrinol. 136, 17-22.

Rouillé, Y., Chauvet, M., Chauvet, J., Acher, R. 1988. Dual duplication of neurohypophysial hormones in an Australian marsupial: Mesotocin, oxytocin, lysine vasopressin and arginine vasopressin in a single gland of the Northern bandicoot (Isoodon macrourus). Biochem. Biophys. Res. Comm. 154, 346-350.

Sawyer, W.H., Munsick, H.B., van Dyke, H.B. 1960. Pharmacological characteristics of neurohypophysial hormones from a marsupial (Didelphis virginiana) and a monotreme (Tachyglossus (echidna) aculeatus). Endocrinol. 67, 137-138.

Sawyer, W.H., Pang, P.K.T. 1975. Endocrine adaptation to osmotic requirements of the environment: Endocrine factors in osmoregulation by lungfishes and amphibians. Gen. Comp. Endocrinol. 25, 224-229.

Sernia, C., Zeng, T., Gemmell, R.T. 1997. Ontogeny of thyroid hormone receptors in the brushtail possum (Trichosurus vulpecula). Repro. Fertil. Dev. 9, 489-492.

Setchell, P.J., 1974. The development of thermoregulation and thyroid function in the marsupial Macropus eugenii (Desmarest). Comp. Biochem. Physiol. 47, 1115-1121.

Seebacher, F., Franklin, C.E. 2001. Control of heart rate during thermoregulation in the heliothermic lizard, Pogona barbata: importance of cholinergic and adrenergic mechanisms. J. Exp. Biol. 204, 4361-4366.

Seebacher F., Franklin, C.E. 2003. Prostaglandins are important in thermoregulation of a reptile (Pogona vitticeps). Proc. Royal. Soc. Lond. B. (Suppl) 270, 550-553.

Seebacher, F., Franklin, C.E. 2004. Cardiovascular mechanisms during thermoregulation in reptiles. Int. Congr. Ser. 1275, 242-249.

Seebacher, F., Franklin, C.E. 2005. Physiological mechanisms of thermoregulation in reptiles: a review. J. Comp. Physiol. B. 175, 533-541.

Seebacher, F., Grigg, G.C. 2001. Changes in heart rate are important for thermoregulation in the varanid lizard, Varanus varius. J. Comp. Physiol. B 171, 395-400. 
Shoemaker, V.H., Nagy, K.A. 1977. Osmoregulation in amphibians and reptiles. Ann. Rev. Physiol. 39, 449-471.

Sköld, H.N., Aspengren, S., Wallin, M. 2012. Rapid colour change in fish and amphibians function, regulation, and emerging applications. Pig. Cell Melan. Res. 26, 29-38.

Somogyi, V., Gyorffly, A., Scalise, T.J., Kiss, D.S., Goszleth, G., Bartha, T., Frenyo, V.L., Zsarnovsky, A. 2011. Endocrine factors in the hypothalamic regulation of food intake in females: A review of the physiological roles and interactions of ghrelin, leptin, thyroid hormones, oestrogen and insulin. Nut. Res. Rev. 24, 132-154.

Szekely, M., Petervari, E., Balasko, M. 2010. Thermoregulation, energy balance, regulatory peptides: Recent developments. Front. Biosci. 2, 1009-1046.

Tattersall, G.J., Eterovick P.C., de Andrade D.V. 2006. Tribute to R. G. Boutilier: Skin colour and body temperature changes in basking Bokermannohyla alvarengai (Bokermann 1956). J. Exp. Biol. 209, 1185-1196.

Thompson, G.G., Withers, P.C., McMaster, K.A., Cartledge, V.A. 2005. Burrows of desertadapted frogs, Neobatrachus aquilonius and Notaden nichollsi. J. Roy. Soc. West. Aust. 88, 17-23.

Uchiyama, M., Konno, N. 2006. Hormonal regulation of ion and water transport in anuran amphibians. Gen. Comp. Endocrinol. 147, 54-61.

Urban, M.C., Phillips, B.L., Skelly, D.K., Shine, R. 2007. The cane toad's (Chaunus [Bufo] marinus) increasing ability to invade Australia is revealed by a dynamically updated range model. Proc. Royal Soc. Lond. B. 274, 1413-1419.

Vleck, C.M., Priedkalns, J. 1985. Reproduction in zebra finches: hormone levels and effect of dehydration. Condor 87, 37-46.

Weaver, D., Walker, L., Alcorn, D., Skinner, S., 1994. The contributions of renin and vasopressin to the adaptation of the Australian spinifex hopping mouse (Notomys alexis) to free water deprivation. Comp. Biochem. Physiol. A. 108, 107-116.

Weiss, M., McDonald, I.R. 1965. Corticosteroid secretion in the monotreme Tachyglossus aculeatus. J. Endocrinol. 33, 203-210.

Williams, J.B., Tieleman, B.I. 2001. Physiological ecology and behaviour of desert birds. Curr. Ornith. 16, 299-353.

Withers, P.C. 1995. Evaporative water loss and colour change in the Australian desert tree frog Litoria rubella (Amphibia: Hylidae). Rec. West. Aust. Mus. 17, 277-281.

Withers, P.C., Cooper, C.E., Buttemer, W.A. 2004. Are day-active small mammals rare and small birds abundant in Australian desert environments because small mammals are inferior thermoregulators? Aust. Mam. 26, 117-124. 


\section{Figures}

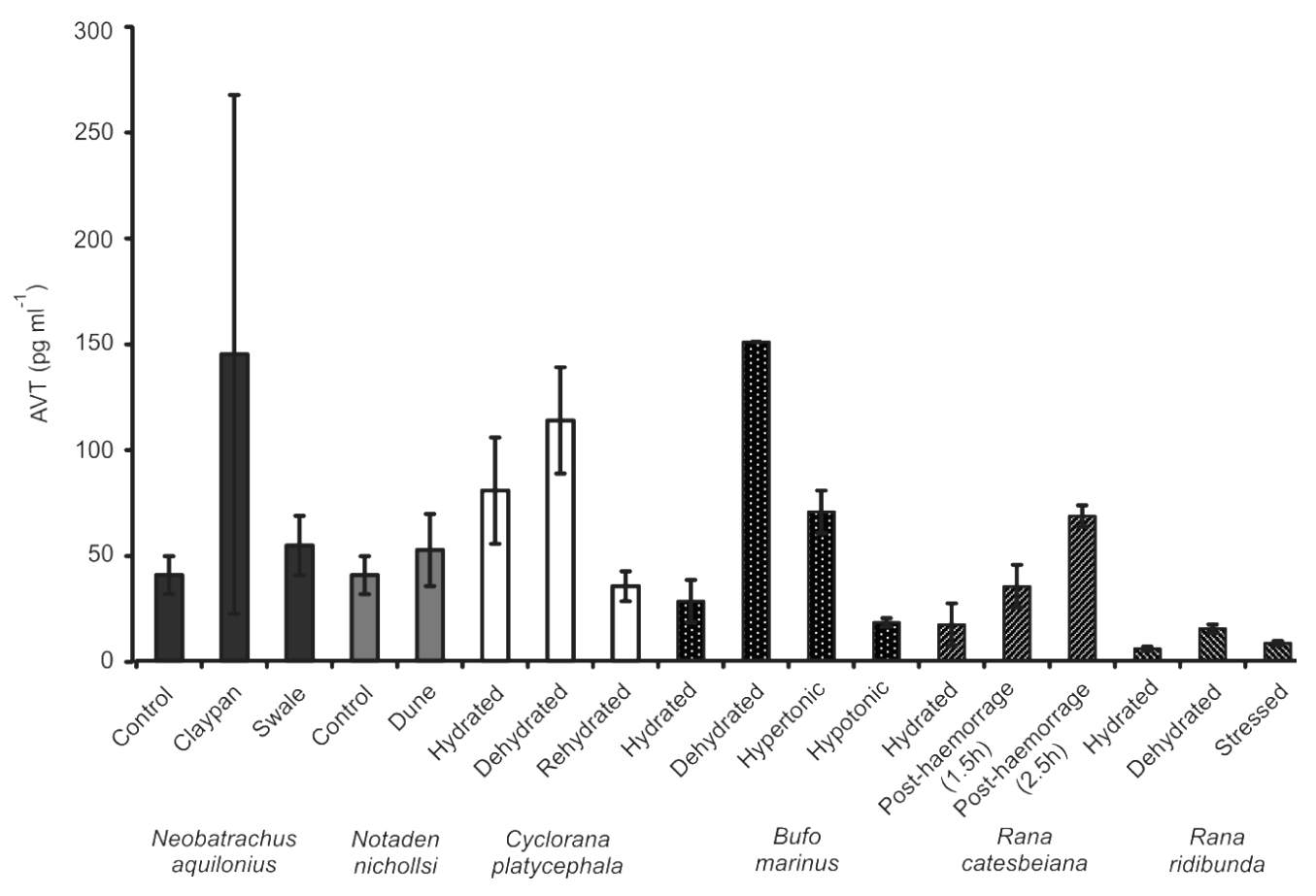

Figure one: Plasma arginine vasotocin (AVT) concentration of the Australian desert Myobatrachid burrowing frogs Neobatrachus aquilonius and Notaden nichollsi aestivating in the Gibson Desert, Western Australia and Cyclorana platycephala aestivating in the laboratory, compared with plasma AVT levels of Bufo and Rana spp. in the laboratory under varying experimental conditions. AVT levels of even control burrowing myobatrachids appear high compared to other taxa, more closely approximating these taxa under physiologically stressful conditions. Values are mean \pm SE, data from Cartledge et al. (2006, 2008), Kono et al (2005), Pang (1977) and Sawyer and Pang (1975). 


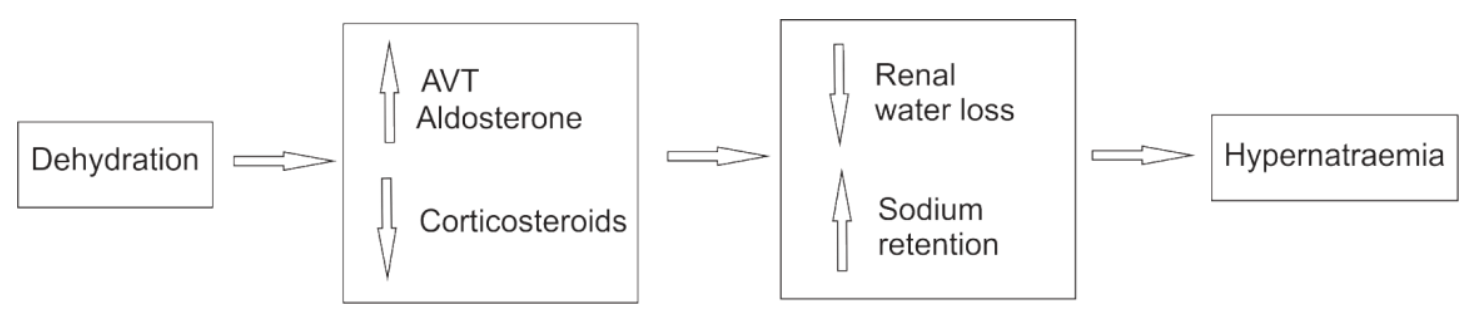

Figure two: Endocrinological studies of Australian squamate reptiles provide a synthetic overview of reptilian responses to dehydration, indicating how these desert tetrapods react to dehydration without the ability to produce urine more concentrated than blood plasma. 


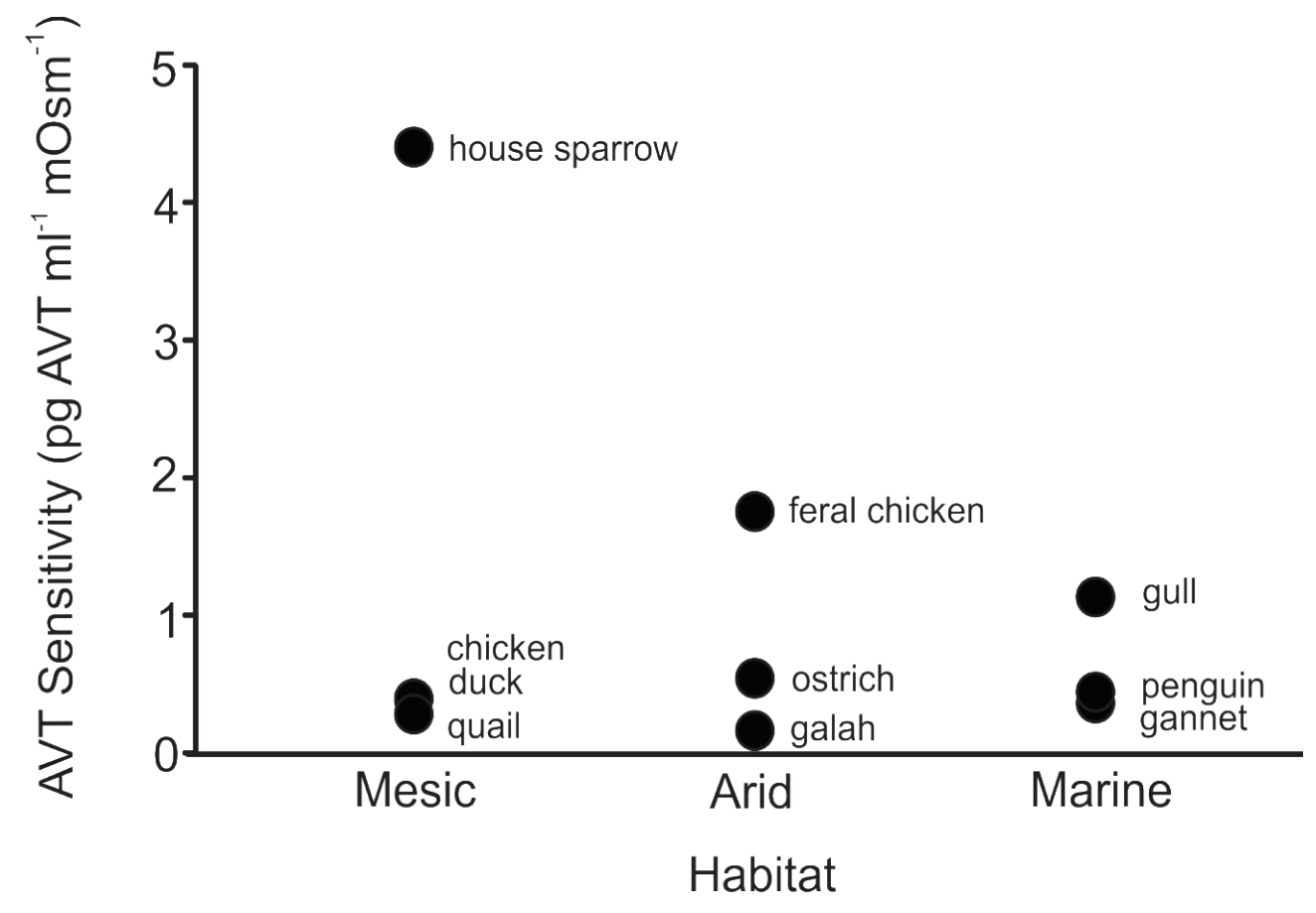

Figure three: Plasma arginine vasotocin (AVT) sensitivity for 10 species of bird from arid, mesic and marine habitats (data from Bentley 2002 and Chaturvedi et al. 2000). There is considerable variability between species, even for species from similar habitats, and no significant habitat effect $\left(\mathrm{F}_{2,7}=0.253, \mathrm{p}=0.783\right)$ on AVT sensitivity. 


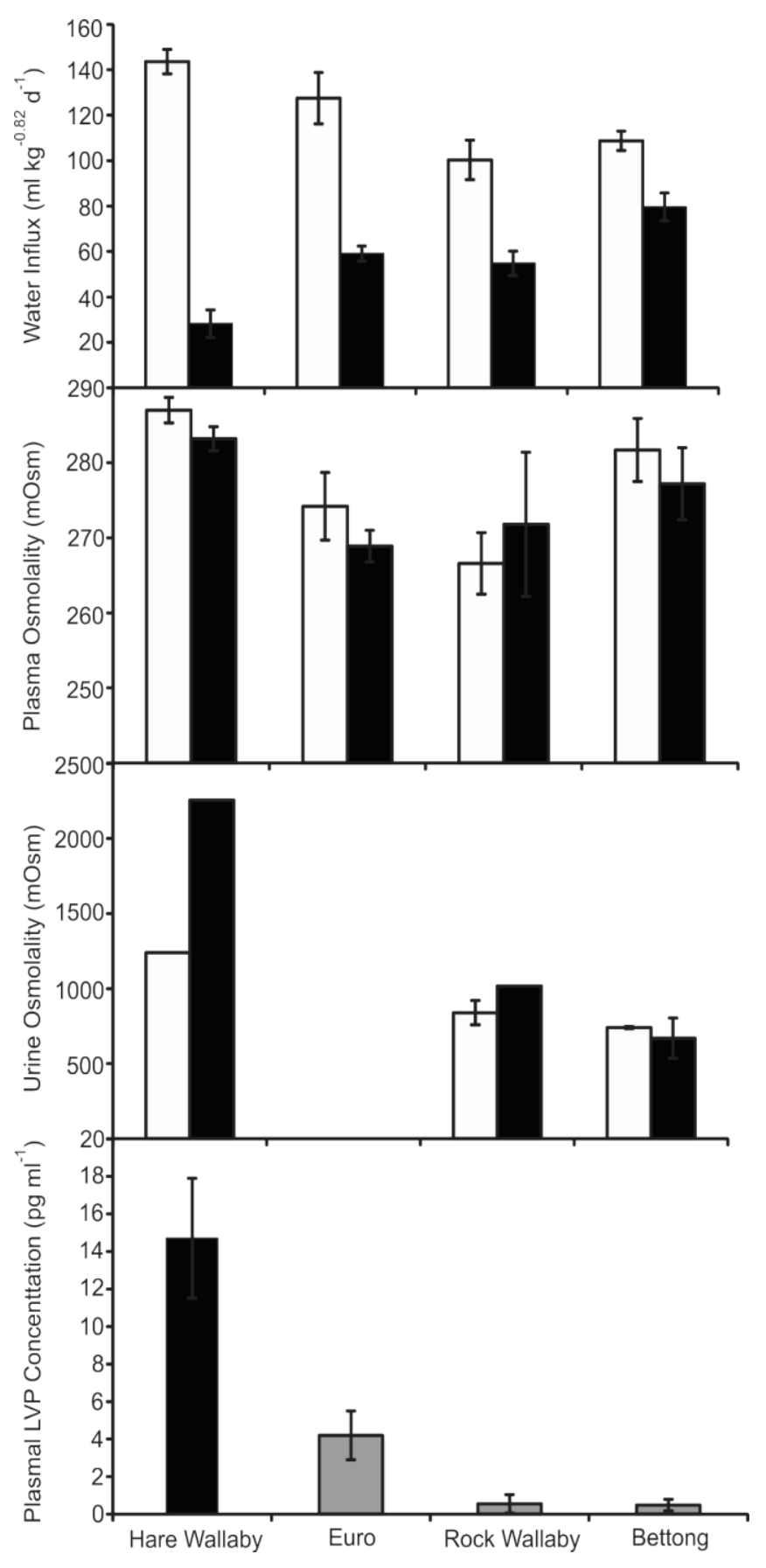

Figure four: Water influx, plasma osmolality, urine osmolality and plasma lysine vasopressin (AVP) for four species of wild, free-living macropod marsupial (spectacled hare wallaby Lagorchestes conspicillatus, Barrow Island euro Macropus robustus isabellinus, black-footed rock wallaby Petrogale lateralis and burrowing bettong Bettongia lesueur), measured on arid Barrow Island, Western Australia during wet (white bars) and dry periods (black bars) from 1990 to 1996. Values are mean \pm SE; grey bars are wet and dry periods combined. Data from King and Bradshaw (2008). 